\title{
II.
}

Aus der Klinik für Nerven- und Geisteskranke zu Kolozsvár (Klausenburg).

\section{Über die syphilitische Erkrankung der Basilararterien des Gehirns.}

\author{
Von \\ Dr. Rud. Fabinyi, \\ Assistent. \\ (Mit Tafel II-IV.)
}

Die Frage nach den syphilitischen Veränderungen der Basilararterien des Gehirns ist besonders hinsichtlich ihrer Lokalisation und Entștehungsweise noch keineswegs gelöst. Die Untersuchungsergebnisse der folgenden drei Fälle vermögen vielleicht zur Klärung der Frage etwas beizutragen.

I.

Anamnese: E. L. 22jähriger Hörer der Medizin. Aufgenommen in die Klinik, für Nerven- und Geisteskranke zu Kolozsvár am 8. Dezember 1901.

Hereditäre Belastung ist nicht nachweisbar. Im Herbste 1899 erkrankte er an hartem Schanker, der jedoch bald heilte. Sekundäre Erscheinungen traten nicht auf. Im Jahre 1900 entstand eine Iritis, die ebenfalls bald heilte. Am 30. Mai 1901 erlitt er einen apoplektischen Anfall, der zu Aphasie und rechtseitiger Hemiplegie führte. Diese Symptome gingen im Verlaufe einer Schmierkur allmählich zurück. Am 11. Juli erlitt der Kranke einen zweiten Anfall, welcher angeblich die Lähmung der linken Körperhälfte verursachte. Auch diese Lähmung verschwand bei Jodtherapie in kurzer Zeit. Am 10. September wurde er zum dritten Male von einem apoplektischen Anfalle heimgesucht, nach welchem Sprachstörungen auftraten; die linke Pupille, sowie die linke Ober- und Unterextremität wurden gänzlich gelähmt und der linke Facialis paretisch. Langsam ging die Lähmung auf die rechte Seite über, und blieb hier beständig, während die der linken Seite sich langsam besserte.

Status praesens: Die rechte Pupille des stark abgemagerten Kranken ist mittelgross und reagiert auf alle Reize gut. Die linke erscheint dagegen stark erweitert and reagiert kaum. Die Augenbewegungen sind frei. Das Gehör ist normal. Schlucken kann der Kranke äusserst schwer und nur Flüssigkeiten. Die Hautempfindlichkeit an der rechten 
Körperhälfte ist gesteigert. Die rechte Körperbälfte ist gelähmt, die obere Extremität bleibt stets in halbkontrahierter Stellung, die nntere Extremität meistens im Knie gebengt. Passiv lässt sich so die untere wie die obere Extremität ausstrecken, beide werden aber anf den kleinsten Reiz wieder eingebogen. Die Muskulatur der gelähmten Extremitäten ist atrophisch, die Reflexerregbarkeit gesteigert, die der linken Seite aber in geringerem Grade. Sprechen kann der Kranke nicht. Schreiben ist er auch unfähig. Zeitweise schneidet er Grimassen, ist unruhig, bewegt seinen gesunden Arm lebhaft. Die somatische Untersuchung ergibt den Puls äussert schwach, aber rhythmisch, die Digestion stark gestört; der Kranke nimmt nur Flüssigkeiten zu sich, trotzdem tritt oft Erbrechen ein. Den Stuhl und Urin lässt er unter sich fliessen. Die Wahrnehmung ist äusserst mangelhaft, er reagiert nur auf unangenehme Reize. Die Orientierung ist in jeder Beziehung ebenfalls unvollkommen. An der gelälmten Körperhälfte treten zeitweise tonische, in den Paroxysmen auch klonische Krämpfe auf. Der Kranke onaniert oft

Verlauf: Am 25. Dezember entstand nach einem epileptiformen Anfalle auf der rechten Konjunktiva ein Bluterguss. In den folgenden zwei Monaten trat keine Veränderung ein. Am 22. Februar erlitt er abermals einen epileptiformen Anfall. Im März verbessert sich sein Zustand, er nimmt auch feste Nahrung zu sich. An den gelähmten Extremitäten entwickelt sich trotz der Massage allmählich eine Kontraktur.

In der Nacht vom 30. März wurde er neuerdings von einem epileptiformen Anfall heimgesucht. $Z$ wei Tage später erlitt er nach vorhergehenden Aufregungen einen apoplektischen Anfall, der von einer bochgradigen Asphyxie und Dyspnoe begleitet war. Er wurde bewusstlos, reagierte gar nicht. Die Temperatur stieg auf $41^{\circ} \mathrm{C}$, Puls 130, filiform. Die Augäpfel bewegen sich nach links. Die Bewusstlosigkeit dauerte drei Stunden. Am folgenden Tage erholte er sich ein wenig. Auch die linke Seite wurde im hohen Grade paretisch. Die Parese schwindet in den folgenden Tagen. Am Abend des 5. April wiederholt sich der Anfall. Der Kranke bleibt bewusstlos, die Extremitäten sind gelähmt. Puls 120, Temperatur 40,8 ${ }^{\circ}$. In diesem Zustande ereilt ihn der Tod.

Sektionsbefund: Beim Eröffnen des Schädels ergiesst sich von der linken Seite auffallend viel gelbes, klares Serum, von der rechten Seite nur wenig seröses oder dünnflüssiges Blut. Die gesamte Menge der aufgefangenen Flüssigkeit betrug $200-300 \mathrm{ccm}$. Die Duramater lässt sich von der inneren Oberfläche des Schädeldaches an einigen Stellen schwer abtrennen. Die Wände sind hauptsächlich der Schläfen und Parietallappen entsprechend anffallend verdickt.

Von der inneren Oberfläche der Dura lässt sich, entsprechend der rechten Gehirnhemisphäre eine feine, an manchen Stellen dichtere, bald dünnere, aber überall vorbandene, durchscheinende Bindegewebsmembran abstreifen. Zwischen der Membran und der Dura sind kleinere, grössere hirsenkorn- bis bohnengrosse Blutergüsse, dem Stirnlappen entsprechend ein Bluterguss von der Grösse einer Kinderhand vorhanden. Die Ergüsse verbreiten sich flach und sind teils aus locker geronnenem Blute, teils aus schon bräunlich gefärbtem, scheinbar sich organisierendem Blutgerinnsel gebildet. Der Raum $z$ wischen den harten und den weichen Meningen, aus dern auch das bei der Eröffnung des Schädels herausströmende Blut 
stammt, erweitert sich nach vorne beträchtlich dadurch, dass der Stirnlappen vorne und oben eine stark eingesunkene Grube bildet, welche von dünnflüssigem, serösen Blute und gestockten Blutschollen ausgefüllt ist. Die erwähnte Membran verliert sich an dieser Stelle gänzlich. An den Meningen der linken Hemisphäre ist ausser dem im Subduralraume in auffallend grosser Menge befindlichem Serum nichts Auffallendes zu sehen.

Das Gehirn ist im allgemeinen abnormal klein. Das Gewicht beträgt ohne die harte Hirnhaut $1140 \mathrm{gr}$. Auf der rechten Seite sind der Gyrus frontalis superior, der obere Rand des Gyrus frontalis medius und der bis zum Sulcus praecentralis sich ausdehnende Teil des Gyrus rectus (also fast die ganze rechte Hälfte des Stirnlappens, ausgenommen den Gyrus frontalis inferior und einen Teil des Gyrus frontalis medius) in der Ausdehnung eines Dreiecks, welches mit der Spitze im Sulcus olfactorius verläuft und mit der Basis gegen den Sulcus praecentralis gerichtet ist, beiläufig in der Länge von $9 \mathrm{~cm}$ und an der breitesten Stelle in der Breite von $3,8 \mathrm{~cm}$, auffallend verändert. Die weichen Hirnhäute sind an diesen Stellen blutreich, die Gehirnsubstanz tief eingesunken, erweicht, und nur an einigen Stellen finden sich härtere Knoten. Ein Schnitt durch die Gehirnsubstanz zeigt die Grenze zwischen der granen und weissen Substanz an allen diesen Stellen verschwommen. Die Gehirnsubstanz ist zu einer gelblich-gräulichen, breiigen, hie und da ein wenig härteren, formlosen Masse verwandelt. Die grösste Breite der nach innen sich ausbreitenden Erweichung beträgt 2,5 cm.

An der linken Hemisphäre ist die Gehirnsubstanz im Bereiche des Gyrus centralis posterior in der Grösse einer kleinen Walnuss erweicht und zeigt die an der rechten Hemisphäre beschriebenen Veränderungen.

Der linke Temporallappen ist an Basis von der Fossa Sylvii bis rückwärts zum Occipitallappen in der Länge von beiläufig $7,5 \mathrm{~cm}$ und in der Breite von $5-6 \mathrm{~cm}$ in ähnlicher Weise erweicht. Die Erweichung dehnt sich also hauptsächlich auf dem Gyrus temporalis medius und inferior aus, doch sind die Ränder des Gyrus Hippocampi und des Gyrus temporalis superior, sowie der Rand des Operculums auch in Mitleidenschaft gezogen. Die Erweichung ist $1 \mathrm{~cm}$ tief. Auf der Schnittfläche sind die Konturen der Windungen scharf gezogen. Die graue Substanz ist durch eine gelbliche undurchsichtige Masse verdrängt. Die weisse Substanz hingegen bildet ein weitmaschiges schwammiges Netzgewebe, dessen Lǚcken mit Serum gefüllt sind.

Die Gehirnsubstanz ist übrigens allgemein ein wenig blutarm, and in Erweichung begriffen. Die Gehirnventrikel enthalten in gesteigerter Menge trübes Serum. Die untere Wand des vorderen Teiles des rechten Hirnventrikels ist in der Grösse eines Pfennigs tief eingesunken. Diese Stelle unterscheidet sich von der Umgebung auch noch durch ihre dunklere, gelblich-gräuliche Färbung. An dieser Stelle befindet sich ein beiläufig haselnussgrosser, dickflüssige, schınutzige, gräulich-gelbe Masse enthaltender Erweichungsherd.

Die äussere und untere Wand des linken Seitenventrikels (also das Corpus striatum und der Thalamus opticus) ist ganz, am auffallendsten im Vorderhorne erweicht, und zwar so, dass sie zu einer pappigen, gräulichgelben, an manchen Stellen fast ganz flüssigen, breiigen Masse geworden 
ist. Die Erweichung umgibt den Seitenventrikel in der Grösse eines Hühnereies. ändert.

Das Kleinhirn, die Brücke und das verlängerte Mark sind unver-

Die Arterien der Gehirnbasis zeigen eine auffallende Veräuderung. Die Art. vertebrales and die Arteria basilaris, sowie die zum Kleinhirn laufenden Äste der letzteren scleinen ziemlich unversehrt. Die Wände der übrigen Arterien sind mehr oder minder verdickt. Die Wandverdickung der rechten Arteria cerebri profunda, Art. fossae Sylvii und der Art. cerebri anterior ist ziemlich beträchtlich. Die Verdickung der kleineren Zweige der Art. corporis callosi, die zum grossen Erweichungsherd der rechten Hemisphäre führen, ist so stark, dass manche ganz obliteriert erscheinen. Die Art. profunda cerebri der linken Gehirnhälfte bildet einen dünnen, derben, zylindrischen Strang ohne Lumen. Auch die linke Art. fossae Sylvii und die linke Hälfte des Cireulus arteriosus Willisii sind in grösserem Grade verändert. Viele Arterien, besonders die Art. fossae Sylvii bilden auf dieser Seite kompakte, strangförmige Gebilde. Am Querschnitte ist die Dicke der Wände, deren Härte und weisse Färbung, hauptsächlich aber das enge Lumen, auffallend. Die Verdickung bildet an manchen Stellen Knoten. Ausnahme macht die Art. corporis callosi, deren Wände nur mässige diffuse Verdickung zeigen.

Diagnose: Endarteriitis proliferans et obliterans verosimiliter syphilitica arteriarum nonullarum basis cerebri subsequente emollitione lobi frontalis dextri, lobi temporalis et gyri centralis sinistri cerebri, necnon corporis striati lateris utriusque. Pachymeningitis interna haemorrhagica hemispheriae dextrae. Hydrops meningum et ventriculorum hemispheriae utriusque.

Histologischer Befnnd. Das Fixieren und die Härtung der Blutgefässe geschah in allen drei Fällen in Formalin, die Färbung der einzelnen Schnitte mit Hämatoxylin-Eosin, Hämatein-Pikrorubin oder Resorcin-Fuchsin. Die Schnitte aus den erweichten Gehirnpartien wurden ebenfalls entweder mit Hämatoxylin-Eosin oder HämateinPilirorabin, oder bei Nachhärtung mit Müllerscher Flüssigkeit nach Weigert gefärbt. Einige Stäcke wurden nach der Methode Marchis bebehandelt.

1. Arterien. Nicht jede basale Arterie erscheint erkrankt. Die grössten Gefässe bleiben (Art. basilaris, Art. vertebrales) unversehrt. Um so mehr sind die grösseren und mittelgrossen Arterien ergriffen, von denen manche ganz obliteriert erscheinen. Die histologische Untersuchung ergab, dass die kleinen Arterien der gesunden Gehirnsubstanz und viele der erkrankten Partien keine krankhaften Veränderungen zeigen. Bezeichnend für dieselben bleibt aber der stark gewundene Verlauf der Elastica and die verdickte Muskularis.

Die grösste Veränderung zeigt die Intima. Wir fanden sie an fast allen untersuchten Gefässen mehr oder minder verdickt. Die Hypertrophie vollzieht sich meist exzentrisch (Fig. 1a), doch manchmal vollkommen regelmässig konzentrisch. Die Proliferation der Intima macht den Eindruck einer jüngeren Erkrankung. Sie zeigt schichtenweise eine verschiedene Strultur. In den älteren äusseren Schichten ist die Intima zellenarm, 
die Zellen haben Fortsätze, sind länglich, die Interzellularsubstanz ist locker und hat stellenweise ganz den Charakter eines hydropisch-sulzigen Bindegewebes. Die inneren frischeren Schichten sind dagegen reich an Zellen, die Granulationsgewebszellen gleichen. Diese Schicht umringt konzentrisch das verengte Lumen, oder bildet rundliche in das Lumen hineinragende, in manchen Fällen dasselbe sogar überbrückende Massen. Ausser der Bindegewebszellenwucherung findet sich beinahe überall mehr oder weniger eine rundzellige Infiltration. Im Anfangsstadium ist die Infiltration so gering, dass sie neben der Proliferation kaum ins Auge fällt.

Bei dem höchsten Grade dieser Endarteriitis proliferans erscheinen einige grössere Gefässe ganz obliteriert (Fig. 2). Die histologische Struktur der Intima entspricht grösstenteils den schon beschriebenen äusseren Schichten, die fortsatzreichen Zellen stehen in der homogenen, gallertartigen Grundsubstanz ziemlich zerstreut. An manchen Stellen, hauptsächlich nach der Mitte des obliterierten Lumens, liegen sie dichter, so dass das Gewebe den Charakter eines Granulationsgewebes annimmt, in welchem auch die neu entstandenen meist blutreichen Gefässe nicht fehlen, manchmal sogar in grosser Zahl vorhanden sind. Ausserdem finden sich teils in den Zellen selbst, teils ausserhalb derselben, kleinere grössere Pigmentkörnchen (Fig. 2 d). Dabei fehlt die rundzellige Infiltration nur selten (Fig. 2 e). Die Struktur des obliterierten Lumens ist an einigen Stellen grobkörnig. Die Körnchen sind wahrscheinlich Überreste des Fibrins und der zugrunde gegangeneu roten Blutkörperchen. Elastische Fasern sind in der neugebildeten Intima nur in einem Falle und $z$ war auf der Oberfläche zu finden. Riesenzellen fanden sich nicht. Von Verkalkung ist keine Spur vorhanden.

Die Membrana elastica interna hat im allgemeinen einen sich stark schlängelnden Verlauf (Fig. 1, Fig. $2 b$ ), ist aber im Vergleiche zu den Veränderungen der Muscularis und der Intima nur in geringem Grade erkrankt. Sie erscheint unverändert selbst an solchen Stellen, wo sie von Infiltrationsherden umgeben wird; in ihrer Nähe sind anch Riesenzellen zu finden. An wenigen. Stellen erscheint sie faserig aufgelöst. In einigen ganz zusammengefallenen Gefässen ist eine neugebildete, an der Oberfläche der proliferierten Intima sich entlang schlängelnde Elastica sichtbar, welche sich unabhängig von der eigentlichen Membrana elastica interna gebiltet zu haben scheint.

In der Media befinden sich an manchen Stellen bedeutende Veränderungen, grösstenteils aber sieht sie trotz der Veränderungen der Intima und Adventitia kaum erkrankt aus. Die Media fast aller Gefässe ist verdickt (wahrscheinlich eine Folge der starken Kontraktion). Die Muskelzellen erscheinen normal. Je nach dem Fortschritt der Erkrankung verdünnt sich die Media und wird schliesslich zu einem narbigen Gewebe umgebildet. In diesem Stadium sind die elastischen Fasern auch atrophisch. Charakteristisch ist, dass die Infiltration oft eine ausgeprägte herdförmige, rundliche Masse bildet, die sich anch auf die Adventitia und in gewissem Grade selbst auf die Intima erstreckt. Solche Herde bergen nebst den kleinen Randzellen noch grosse epitheloide Zellen (Fig. 1e). Ausser diesen Herden fanden sich einige in der Media, in nächster Nachbarschaft der Elastica, aus Riesenzellen bestehend, umgeben von diffuser geringer Infiltration und einigen epitheloiden Zellen (Fig. 2h). Die fortgeschrittensten 
Phasen der Erkrankung zeigt die Media dort, wo sich die Membrana elastica interna von der atrophischen Media hebt und sich ein Granulationsgewebe mit Granulationszellen, zahlreichen Gefässen und Pigmentkörnchen entwickelt hat, dessen Gewebsstruktur somit dem Gewebe der obliterierenden Intim a ähnlich wird.

Auch die Veränderungen der Adventitia sind entzündlicher Natur. Sie ist zellreicher, enthält an manchen Stellen zahlreiche Pigmentkörner, die in dem durch neugebildete Gefässe durchzogenen Granulationsgewebe sitzen. An vielen Stellen findet sich nebenbei eine entzündliche Infiltration. Diese Infiltration besteht teils aus unregelmässigen kleineren, teils aus rundlichen grösseren Herden. Den Mittelraum einiger solcher Herde füllen epitheloide Zollen aus. Diese werden von einem Ringe lymphoider Zellen umgeben (Miliare (Fig. 3d). An manchen Stellen finden sich noch von Rundzellen umlagerte Riesenzellen.

Die Veränderungen der Adventitia und der Intima halten nicht immer gleichen Schritt. Bei der Endarteriitis proliferans tritt die grösste Infiltration in der Adventitia dann auf, wenn die Intima ebenfalls Proliferationen zeigt. Die Membrana elastica interna und die ganze Muscularis bleiben zumeist unversehrt. An manchen Stellen zeigt die Adventitia trotz hochgradiger Endarteriitis das Bild eines fast gesunden Gewebes. Die herdförmigen Entzündungsveränderangen der Media stehen mit den ähnlichen Vorgängen der Adventitia nicht immer in Zasammenhang. Noch weniger lässt sich, wie schon erwähnt, das Überschreiten der Intimaveränderung auf die Media bestimmt nachweisen.

2. Gehirnsubstanz und weiche Hirnhäute. Die aus den verschiedenen Teilen des Gehirns gewonnenen Präparate zeigen verschiedene Stadien der Erweichung. Das Auftreten und Fortschreiten der Erweichung vollzieht sich anch hier in der bekannten Reihenfolge.

Viele makroskopisch scheinbar unversehrte Gehirnpartien erweisen sich unter dem Mikroskop als krank, was besonders bei der Weigertschen Färbung ins Auge fällt. Die Markscheiden erscheinen auch an Stellen, die von den Erweichungsherden entfernt liegen, stellenweise zerbröckelt, varicös. Ihr Verlauf ist schwer zu verfolgen. An anderen Partien ist ihre Zahl geringer, so dass sich im dunkelblanen Felde lichte und leermaschige Stellen bilden. Nach Marchi gefärbt enthalten die Markscheiden in diesen Stadien der Erkrankung unzählige Fettkörnchen. Die Neurogliazellen schwellen an und färben sich ganz homogen rosenrot, (Hämatoxylin-Eosin) oder lichtbraun (Weigert). Von den degenerierten Nervenzellen kann man sie auch dort gut unterscheiden, wo sie homogene Massen mit verwischten Grenzen bilden, da sie Fortsätze haben und nicht in Zellenräumen sitzen. Neben den geschwollenen Gliazellen findet man auch ganz normale.

Am Rand der Erweichung sind die Nervenzellen wenig verändert. Doch früh lässt sich schon mit der Mar chi schen Methode eine Fettkörnchenbildung nachweisen. Wit dem Auftritte der Körnchenzellen verschwinden die Nervenzellen äusserst rasch. Es bleibt dann bloss ein körniger Detritus an ihrer Stelle zurück. Als Übergangsfor'men beobaclitete ich hydropische Degeneration: der Kern und der Zellkörper schwellen stark an, ibre Struktur wird homogen. Das Bild der beginnenden Erweichung ist nicht immer das gleiche. Das 
Gewebe wird locker, wenn die Nervensubstanz zugrunde gegangen ist, ein Unterschied bestehlt aber dennoch darin, dass dort, wo die Neurogliazellen in grösserer Zahl vorhanden sind und ein enges Netzwerk bilden, das Gewebe konsistenter bleibt. Hingegen dort, wo Neurogliazellen kaum mehr vorhanden sind, vielmehr die ganze Substanz in ein körniges, viel.Fett enthaltendes Detritusgemenge zerfallen ist, das Gewebe locker wird.

Das zweite Stadium des Erweichungsprozesses wird durch die grosse Zahl der Körnchenzellen charakterisiert. Diese Zellen überwuchern alles Übrige dermassen, dass durch ihre gelbe Färbung schon makroskopisch sichtbare Zonen entstehen. Die Körnchenzellen sind ziemlich grosse, rundliche Zellen, mit scharfen Konturen, die nebeneinanderliegend sich polygonal abflachen, so dass sie an manchen Stellen den Epithelzellen täuschend ähnlich sehen. Thr Protoplasma ist mehr oder minder gekörnt, von nach Marchi schwarz gefärbten, zahlreichen nadelförmigen Fettkristallen durchsetzt, welche massenhaft aufeinanderliegen. Dort wo die Körnchenzellen mehr zerstreut liegen, wo also der Zerfall der Gewebe erst vor kurzem begonnen hat, häuft sich das Fett zu Tropfen an. Wahrscheinlich lösen sich diese Tropfen im Zellplama später auf, um sich dann zu kristallisieren. Denn in kristallinischer Form findet sich das Fett nur in den Körnchenzellen. Der Zellkern der Körnchenzellen liegt exzentrisch, ist klein und färbt sich gleichförmig dunkelblau. Dort wo die Körnchenzellen auftreten, gehen die übrigen Elemente der Gelirnsubstanz stufenweise zugrunde. Erst schwinden die Nervenzellen, dann die in Markscheiden gehüllten Nervenfasern. IDie Gliazellen schwellen anfangs auf, um dản zu degenerieren. An manchen Stellen sind die Gliazellen in Form grosser, brauner, homogener Flecken gut sichtbar. Dieselben sind von zwar noch erhaltenen, aber degenerierten, sich blau färbenden, markscheidigen Nervenfasern umgeben, die ein loses Netz bilden (Weigerts Färbung). In den vorgerückten Stadien kommen auch die Nervenfasern und Gliazellen zum Zerfall, und verschwinden allmählich. Alle diese Elemente werden von den Körnchenzellen aufgenommen und einverleibt.

Eine eigentümliche Erscheinung ist, dass in einigen, schon ganz zugrunde gegangenen Windungen sich die Körnchenzellen senkrecht zur Gyrus-Oberfläche aufstellen, wodurch Querstreifen zustande kommen, die nach Marchi gefärbt am besten ins Auge fallen. Die Körnchenzellen finden sich in grosser Zahl, ausser in den von ihnen gebildeten Zonen, noch in manchien perivaskulären Lymphräumen, wo sie um das betreffende Gefäss einen dichten Mantel bilden.

Die dritte Stufe des Erweichungsprozesses zeigt sich im Bilde des "état criblé", das makroskopisch als ein, von der gelben Zone der Körnchenzellen umschlossenes, gräulich gefärbtes, ganz lockeres, fast zerflossenes Gebilde erscheint. - Die ursprüngliche Substanz des Gehirngewebes ist mit Ausnahme der durchlaufenden Gefässe, gänzlich verschwunden. Die Gefässe sind weit, mit Blut gefüllt, und liegen an manchen Stellen sehr dicht aneinander; ein Teil derselben scheint neugebildet za sein. Zwischen den Capillaren liegt ein sehr lockeres, weitmaschiges, an manchen Stellen fleckenweise dichtes Netzwerk von Bindegewebe, das seinen Ursprung aus den Wänden der Kapillaren za nehmen scheint und aus grossen, langen, spindelförmigen Zellen besteht: In diesem Netze liegen stellenweise, besonders um die grösseren Gefässe gelagert, mehrere oder einzelne Körnchen- 
zellen. In der Mitte der Erweichungsherde ist neben dem Bindegewebsnetze kein weiteres Gewebselement mehr zu sehen. Auffallend ist es, dass die Nervensubstanz an manchen Stellen fleckenweise erhalten ist. Diese Stellen erscheinen bei Hämatoxylin-Eosin-Färbung als homogene, rosenrote, amyloidähnliche Flecken, während bei der Weigertschen Färbung das lockere Geflecht der äusserst degenerierten Markscheiden sichtbar wird. Wahrscheinlich sind es funktionsunfähige, aber noch nicht ganz resorbierte Nervenfasern.

Von Interesse ist die Tatsache, dass die unmittelbar unter der Ependyma des Ventrikels und unter der Pia und deren Septa gelegene Schichten der Rinde nirgends ergriffen sind, vielmehr, ausser wenigen entzündlichen Veränderungen, intakt erscheinen. Die Erweichung beginnt immer nur unter einer unversehrten Schicht, und geht stufenweise in das "état criblé" über. Die Ursache ist gewiss darin zu suchen, dass einerseits zwischen der Tela choroidea und der Ependyma, anderseits zwischen der Pia und der Gehirnrinde, feine, zur Ernährung der oberflächlichen Schichten dienende, Anastomosen bestehen.

Ausser diesen degenerativen, sekundären Veränderungen begegnen wir zuweilen auch Erscheinungen entzündlicher Natur. Zuerst fällt die Infiltration der Pia auf, welche beinahe überall vorhanden und mehr perivaskulär ist. Auch diffuse InfiItration findet sich zuweilen, aber nicht besonders verbreitet. Rings um die tiefen Gefässe der Gehirnsibstanz trifit man meistens eine starke Infiltration. Bemerkenswert ist dabei, dass neben starken perivaskulären Infiltrationen auch ganz infiltrationslose Gefässe zu sehen sind. Die Gefässe erscheinen dann ganz intakt, an den grösseren ist die Media verdickt und die Elastica schlängelt sich. Einer ganz diffusen rundzelligen Infiltration begegnen wir auch in der zugrunde gegangenen Gehirnsubstanz. An manchen Stellen ist die Infiltration im "état criblé" reicher als sonstwo, sie verdickt sich sogar zu einigen grösseren, gut umschriebenen Herden, welche sich öfter in der Nähe der kleinen Gefässe anhäufen. Diese Herde bestehen hauptsächlich aus Rundzellen, in deren Mitte auch gut abgegrenzte, kernige, epitheloide Zellen in grosser Zaht anzutreffen sind. An mehreren Stellen findet man in der Mitte diffuser Infiltration, unter dem Ependym, auch Riesenzellen mit zahlreichen randstelligen Zellkernen.

Die Struktur der harten Hirnhaut scheint normal zu sein. Nur stellenweise ergeben sich kleinere Blutungen in ihr. Die neugebildete Membran liegt eng an der Dura. Die Struktur der Membran entspricht einem frischeren Granulationsgewebe mit vielen angeschwollenen Bindegewebszellen und zahlreichen, blutreichen Kapillaren. In den der Dura näher liegenden Schichten finden sich Blutungen von kleinerem Umfange. Auch in der Membran sind kleine, rundzellige Infiltrationen beinahe überall vorhanden, aber nur unregelmässig zerstrent und nirgends in grösserem Mabstabe. Besonders an der Oberfläche der Membran liegen Pigmentkörner. Riesenzellen sind nirgends zu finden.

II.

L. B., 32 jähriger Bergwerksbeamter, aufgenommen auf die Klinik für innere Medizin zu Kolozsvár, am 11. März 1902. 
Anamnese: Hereditäre Belastung nicht nachweisbar. Patient belram als Soldat einen harten Schanker, welcher in einem Monate abheilte. Im Sommer 1901 gebrauchte er eine Schmierkur, machte aber nur zwei Touren durch. Seit 8 Jahren ist er verheiratet und hat 5 lebende Kinder. Den vorigen Sommer litt er 5 Monate lang an Kopfschmerzen. Seit beiläufig 5 Wochen fühlt er wieder fortwährende, heftige Schmerzen in der rechten Kopfhälfte, kann deshalb nachts nicht schlafen.

Status praesens. Patient hat einen mittelkräftigen Bau, ist abgemagert, etwas blutarm. Die inneren Organe scheinen nicht verändert. Puls, Temperatur normal. Leidet an Obstipation.

Die Pupillen sind mittelweit und reagieren gut. Am Augengrunde keine Veränderungen. Die übrigen Sinnesorgane funktionieren auch gut. Das Allgemeingefühl ist wegen den fortwährenden reissenden Schmerzen schlecht. Der geistige Zustand zeigt keine krankhafte Erscheinung.

Verlauf: Bis zum 10. April keine Veränderung. Er klagt immerfort über quälende Kopfschmerzen, schläft nur auf grössere Dosen von Aspirin oder Trional.

Am 11. April stellt sich Doppelsehen ein. Das linke Auge ist halbgeschlossen, doch kann es auch ganz geöffnet werden. Die linke Pupille ist weiter und reagiert nur in geringem Maße. Das linke Auge bewegt sich nur nach aussen frei, nach innen kaum. An den nächsten drei Tagen ist der Patient äusserst somnolent. Es stellen sich einige Erbrechungen ein.

Am 15. April leidet er an starken Augenschmerzen. Er sieht mit dem linken Auge allerlei sich bewegende Gegenstände. Visus auf dem linken Auge $6 / 24$, auf dem rechten $6 / 18$. Atrophie der Papilla lässt sich nun schon konstatieren, aber keine Spur einer Stauung. Die Okulomotoriuslähmung am linken Auge hat sich fast vollständig entwickelt.

Am 19. verliess der Kranke die Abteilung und wurde zum zweiten Male am 4. Oktober 1902 aufgenommen.

Patient lag, seitdem er das Spital verlassen hatte, zu Hause krank darnieder. Vor zwei Monaten wurden seine rechten Extremitäten plötzlich gelähmt. Die Lähmung gab mit der Zeit nach, so dass er seinen Fuss wieder bewegen konnte; später gelingen Gehversuche; der Arm aber bleibt wenig beweglich.

Patient ist äusserst abgemagert. An der rechten Hüfte und an der Kreuzgegend befindet sich ein beginnender Decubitus.

Patient schläft den grössten Teil des Tages. Seine Antworten sind kaum verständlich. Er ist äusserst apathisch und macht den Eindruck eines Schwerleidenden. Auch jetzt klagt er über Kopfschmerzen und zwar fühlt er den Schmerz manchmal auch in der linken Kopfhälfte. Die rechte Gesichtshälfte ist paretisch, die rechte Lidspalte etwas weiter als die linke. Bei mimischen Bewegungen bleibt die rechte Gesichtshälfte hinter der linken zurück. Die ausgestreckte Zunge weicht nach rechts ab. Die linke Pupille ist weiter als die rechte, reagiert auf Licht gar nicht. Am linken Auge ist auch Ptosis vorhanden. Die rechte obere Extremität wird stets an den Rumpf adduziert, im Ellenbogengelenke gebeugt, die Hand und die Finger in halbgebogener Stellung gehalten. Die passive Abduktion des Oberarmes gelingt bis auf $45^{0}$, eine aktive Bewegung ist unmöglich. In dem 
Ellenbogengelenke kann der Patient auch ohne Hilfe den Arm ein wenig strecken oder beugen, die vollständige Extension ist auch passiv nicht möglich. Die Hand und alle Finger bewegt der Kranke gut, doch ist die Bewegung etwas langsamer als an der gesunden Seite. Die Druckkraft der rechten Hand ist geringer. Der Knochenhautreflex der rechten oberen Extremität ist etwas lebhafter. Die Patellarreflexe sind an beiden Seiten gesteigert. Der Kranke lässt Kot und Urin unter sich fliessen.

In den folgenden zwei Monaten erhielt der Patient jeden fünften Tag eine Sublimatinjektion. Sein Zustand verschlimmerte sich trotzdem. Der Decubitus heilt zwar ab, die Sprache wird aber gänzlich unverständlich. Die Hand zittert fortwährend, mit den Augen zu fixieren ist er unfähig, die Augenbewegungen sind überhaupt bescluränkt. Der Kranke wird immer unruhiger, spricht fortwährend; bei Nacht ist er äusserst unruhig. Die Temperatur ist beständig subfebril. Der Puls 90 per Minute.

Anfangs Dezember wird er etwas ruhiger, begeht zeitweise verkehrte Handlungen. Das Sensorium ist getrübt. Auf Anreden horcht er noch aufmerksam. Der Patellarreflex der rechten Extremität ist etwas schwächer als der linksseitige.

Mitte Januar entstehen an der linken Hüfte, an dem linken äusseren Knöchel, sowie an der äusseren Seite des ersten Mittelfussknochens mehrere sich immer mehr exulcerierende Decubitusse. Unter dem linken inneren Knöchel entstand auch eine taubeneigrosse Blase, aus der reines Serum floss.

Patient wird immer schwächer, die Decubitusse vergrössern sich von Tag zu Tag, auch treten neue auf, dort wo beim Liegen die Weichteile von Knochen gedrückt werden. Der Puls ist immer schnell, klein und leer. Urin und Kot lässt er unter sich.

Am 22. Februar in der Frühe beginnt die Agonie, um $1 / 2$ Uhr nachmittags stirbt der Kranke.

Die Diagnose wurde auf Tumor cerebri gestellt.

Aus dem Sektions-Protokoll ist folgendes bemerkenswert.

Auf der Haut mehrere tiefgehende Decubitusse.

Das Schädeldach ist spongiös, zeigt tiefe Eindräcke. Die harte Hirnhaut ist etwas gespannt. Der Sinus longitudinalis enthält dunkelrotes, flüssiges Blut.

Die weichen Hirnhäute sind verdickt, an der Konvexität des Gehirns durchscheinend, gallertartig, sehr ödematös, die Gehirnwindungen blicken durch. Die weisse Verdickung der weichen Hirnhäute ist an dem vorderen Teile der Parietallappen und der beiden Stirnlappen am stärksten ausgeprägt. Hier scheinen nur die Konturen des Gehirns durch. Die weichen Hirnhänte sind mit der Dura mater an der Basis stärker verwachsen. Besonders in der rechten, mittleren Schädelgrube fällt das Abpräparieren schwer. Das Tentorium cerebelli ist auch verdickt. Die rechte, mittlere Schädelgrube, die etwas tiefer ist, wird von einer pelzigen Masse bedeclit. Auf der Gehirnbasis ist die Ungleichheit der Temporallappen auffallend, der vordere Teil des rechten Temporallappens ist verflacht and erweicht. Die Windungen sind abgeplattet und fliessen ineinander. Diese Verände- 
rungen dehnen sich vom vorderen Pole nach hinten bis auf $45 \mathrm{~cm}$ aus, nach der Seite auf $4 \mathrm{~cm}$. Ein Schnitt in den Hirnlappen zeigt sofort, dass nicht nur die Rinde, sondern auch die Marksubstanz elweicht ist. Letztere ist von dem Lobus frontalis beginnend bis zum Nucleus lenticularis in eine gallertartige, gelblichgraue Substanz umgewandelt. An einigen Stellen zeigt sie eine siebartige Struktur, die durch ein graues Bindegewebsnetzwerk durchzogen ist, Die Maschen des Netzes sind durch durchscheinendes Mark ausgefüllt. Die graue Substanz der Gehirnrinde scheint dagegegen noch ziemlich unversehrt, sie ist etwas schmäler und weicher. Ausser diesem findet sich kein Erweichungsherd in der Gehirnrinde.

Die beiden Hälften des Gehirns sind wegen der hochgradigen Verdickung und dem Zusammenwachsen der weichen Hirnhäute schwer voneinander zu trennen. Die Arteriae corposis callosi sind an beiden Seiten unversehrt. Die Gehirnventrikel sind etwas erweitert und mit reinem Serum. gefüllt. Das Ependyma ist verdickt und granuliert. An dem linken Corpus striatum befindet sich eine beiläufig pfenniggrosse Einsenkung, welche in gelblicher Farbe durchscheint. Eine ähnliche, kleinere erbsengrosse Einsenkung befindet sich an dem hinteren Teile des rechten Corpus striatum. Das letztere ist anch ein wenig verflacht.

Die rechte Arteria vertebralis ist bei weitem schmäler als die linke, sie beträgt kaum $1,5 \mathrm{~mm}$ im Durchmesser und erscheint als ein solider, walzenförmiger Strang. Im Durchschnitte zeigt sich die Wand verdickt, das Lumen hat kaum die Breite eines Nadelstiches. Der untere Teil der Arteria basilaris erscheint normal, die Wand ist dünn, flach zusammengesunken. Beiläufig an der Mitte der Brücke ist an ihr ein hanfkorngrosser Knoten sichtbar. Nachher verschmälert sie sich und wird solider, obliteriert aber nicht vollständig. Die beiden Arteriae carotides internae sind dicker und enger als im normalen Zustande. Die Art. fossae Sylvii ist rechts fast gänzlich obliteriert.

Weder ein umschriebenes Gumma, noch eine Geschwulst war in dem Gehirn zu finden.

Die linke Lunge ist frei. Die rechte ist an der Pleura angewachsen. Beide sind schwarz pigmentiert. Aus dem Hilus der rechten Lunge beginnend, läuft entlang des oberen Teiles, am unteren Lappen, ein fast kleinfingerdickes, weisses, narbiges Bündel nach der konvexen Oberfläche der Lunge, welches von da auch in den oberen Lappen eindringt und dort ausstrahlt.

Die Milz ist flach, doch länger und breiter als normal. An der konvexen Oberfläche sitzt eine knorpelige Verdickung von der Grösse eines Zweimarkstückes.

An der Oberfläche der Nieren sind einige punktförmige Blutungen sichtbar.

An der Konvexität des rechten Leberlappens ist fast in der Mitte eine $2 \mathrm{~cm}$ lange und $1,5 \mathrm{~cm}$ breite, sich stark vertiefende strahlenförmige Narbe. Von da laufen nach allen Richtungen $1,5-2 \mathrm{~cm}$ lange, tiefe, sich langsam verschmälernde Furchen. An der Durchschnittsfläche ist eine schmale, kaum $4-5 \mathrm{~mm}$ breite Narbe zu sehen, welche mehr als $3 \mathrm{~cm}$ tief in die Lebersubstanz eindringt. In der Narbe sind die Wände der Gefässe äusserst dick. Ausserdem ist die Leber atrophisch. Neben dem Ligamentum suspen- 
sorium an dem oberen Teile des linken Lappens befindet sich eine unregelmässige Narbe, in deren Schnittfläche die Gallengänge etwas erweitert erscheinen.

Beiläufig an der Mitte der vorderen Wand des Rektums befindet sich eine wenig eingesunkene, gräulich pigmentierte Narbe.

Der rechte Hoden ist äusserst klein, weich. An der Schnittfläche dehnt sich, dem Corpus Highmori entsprechend, eine ziemlich grosse Narbe aus, von welcher strahlenförmige Narbenzüge in die Hodensubstanz laufen. Zwischen den Membranen des linken Hodens ist beiläufig 10 gr Serum angesammelt. Der linke Hoden ist nicht grösser, die Hüllen sind stellenweise zusammengewachsen. An der Schnittfläche zeigen sich ähnliche Veränderungen wie an dem rechten Hoden.

Der obere, hintere Teil der Wirbelsäule ist mit einer Konvexität nach links stark gekrümmt. An dem Rücken- und Lendenmark sind die weichen Meningen etwas verdickt. Der Horizontalschnitt des Rückenmarks zeigt keine bemerkenswerten Veränderungen.

Diagnose: Pachymeningitis et leptomeningitis chronica adhaesiva syphilitica praecipue ad basim cerebri. Endarteriitis syphilitica arteriae vertebralis dextrae et fossae. Sylvii utriusque lateris, subsequente emollitione lobi temporalis dextri et corporis striati lateris utriusque. Ependymitis chronica fibrosa, hydrocephalus chronicus. Anthracosis et oedema pulmonum. Cicatrix syphilitica lobi inferioris pulmonis dextri, synechia ejusdem pulmonum. Cicatrix syphilitica hepatis. Orchitis interstitialis syphilitica. Perisplenitis callosa. Hyperplasia lienis. Nephritis haemorrhagica. Cicatrix intestini recti. Decubitus.

Mikroskopischer Befund. 1. Arterien. Überaus auffallend ist die Proliferation der Intima. Sie ist entweder konzentrisch (Fig. IV) (rechte Art. vertebralis), oder exzentrisch (Fig. V), oder aber unregelmässig. Die Intima erscheint an den meisten Präparaten in auffallenderweise zellenarm, sogar in den Anfangsstadien der Erkrankung. Die proliferierte Intima bildet Schichten, die sich besonders in vorgeschrittenen Stadien, gut unterscheiden lassen. Es scheint als ob während der Proliferation die Auflagerung stufenweise erfolgt sei (Fig. $V$ c. c.), der den normalen am nächsten stehenden Formen ist neben der Elastica, also am äussersten Teil der Intima, eine zellreichere Schicht zu unterscheiden. Die folgende mittlere Schicht ist die breiteste, sie ist zellenarm, die Zellen sind sternförmig. Die Interzellularsubstanz erscheint sulzig und homogen. Die dritte ganz unter dem Endothel liegende Schicht besteht aus konzentrisch geordneten, länglichen Zellen (Fig. IV). Eine rundzellige Infiltration ist nur spärlich vorhanden. Der Übergang zwischen diesen Schichten ist kein jäher, sie bilden keine scharf gezogenen Grenzen. In der verdickten Intima liegen stellenweise selbständige Knoten, welche aus dicht liegenden länglichen Zellen bestehen und bei näherer Untersuchung sich als Bündel quergeschnittener Muskelzellen erweisen (Art. fossae, Sylvii). An manchen Stellen ist die Proliferation der Intima äusserst unregelmässig, es scheinen aus ihr Zapfen gegen das Lumen zu wachsen, welche das Lumen auch septenartig teilen können und mehrere grössere und kleinere Lumina bilden, so dass es den Anschein hat, als ob mehrere kleinere Ge- 
fässe von einem gemeinsamen grossen Gefäss bündelweise umschlossen wären (Art. fossae Sylyii). Mit dem Fortschreiten des Prozesses entwickeln sich tatsächlich in der Proliferation kleine neue Gefässe, die manchmal in den tieferen Schichten in grösserer Anzahl nebeneinander liegend rorkommen.

Auffallend ist das Verhalten der elastischen Fasern, Solche tinden sich nämlich in der neugebildeten Intima fast überall. Die vorhandenen Lumina sind durch eine neugebildete, ziemlich dicke, ununterbrochene, sich fast regelmässig schlängelnde Elastica umgeben, welche unmittelbar unter dem Endothel liegt (Fig. V. d.). Dort wo eine solche Elastica nicht rorhanden ist, hat die, das Lumen unmittelbar umgebende Schicht der Intima den Anschein eines ganz jungen Gewebes. In den tieferen Schichten der Intima fanden sich an mehreren Stellen schlängelnd verlaufende, sich verdünnende, manchmal aber um das ganze Lumen sich schlingende, die Intima in Schichten teilende, feinere, elastische Lamellen (Fig. V. $d_{2}$ ). Auch diese sind nur in denjenigen Fällen aufzufinden, in denen die histologische Struktur der Intima auf eine sehr langsam, stufenweise fortschreitende Proliferation hinweist. Der Zusammenhang zwischen der eigentlichen Membrana elastica interna, und diesen elastischen Membranen ist an manchen Stellen gut zu ersehen. In den meisten Fällen aber weist nichts auf einen Zusammenhang hin, sondern die neuen Schichten erscheinen wie neue Produkte, welche immer nur bei dem Stillstand der Proliferation zustande gekommen sind (Fig. V).

Die Proliferation hat ihren grössten Grad in der rechten Art. vertebralis erreicht (Fig. IV), zu vollständiger Obliteration aber ist es weder da, noch in der Art. fossae Sylvii gekommen.

In manchen Arterien (linke Art. fossae Sylvii) finden sich auch Thromben. Dieselben sind teils frei, teils an manchen Stellen mit der proliferierten Intima verwachsen.

Verkalkung ist in der Intima nirgends zu sehen.

Die Membrana elastica interna ist überall gut erhaiten und zeigt auch in der späteren Phase der Erkrankung keine Unterbrechung. Sie ist im allgemeinen verdiclst, scheint aufgequollen and färbt sich oft fleckig. Bei Resorcin-Fuchsin-Färbung scheint sie aus zwei Lamellen zu bestehen, von denen die innere Lamelle dicker ist und sich dunkler und blau färbt; die äussere ist schmäler und zeigt eine lichtere und mehr rötliche Färbung. Die beiden Lamellen berühren sich stellenweise, um bald wieder voneinander zu rücken. Manchmal sind auch mehrere Lamellen zu sehen, welche aus der Auffaserung der einheitlichen Elastica stammen (Art. vertebralis) und zwischen denen an manchen Stellen auch neugebildetes, der proliferierten Intima gleichendes Gewebe Platz nimmt. An anderen Stellen wieder (Art. fossae Sylvii) entfernen sich die zwei Hauptlamellen der Elastica weit voneinander und zwischen ihnen laufen dann feine elastische Fasern (Fig. $\mathrm{V}$ e).

Die Media ist mit wenigen Ausnahmen nur in den späteren Phasen verändert. Manchmal erscheint sie neben der schon stark proliferierten Intima äusserst verdünnt. Fs scheint als ob sie durch die verdickte Intima anseinander gepresst würde. Nicht unmöglich ist es aber, dass sie infolge der Verdickung der Intima ausser Aktion gesetzt und dadursh atrophisch 
wurde. Von Infiltration ist anfangs keine Spur, später ist sie auch nur unbedeutend, und da scheint sie von aussen einzudringen. In diesem Falle fangen die Zellen der Media an zu atrophieren, die Media versclımälert sich, verschwindet stellenweise sogar gänzlich, um einem Granulationsgewebe Platz zu machen (Art. fossae Sylvii).

Auch die Adventitia erscheint schon anfangs etwas infiltriert, besonders die an der Grenze der Adventitia und Media gelegene Lymphspalte (Fig. IV). Aber nur später wird die Infiltration intensiver und beharrt auch in den spätesten Phasen, während sie in der Intima und Media abnimmit. Die Infiltration ist meistens eine diffuse, später tritt sie auch haufenweise auf. Spezifische histologische Produkte (Gummata) sind nirgends zu finden.

2. Gehirnsubstanz und weiche Hirnhäute. An der Peripherie der Erweichungsherde ist die Auflockerung der Gehirnsubstanz, die Degeneration und das gänzliche Verschwinden der Nervenzellen zu ersehen. Weiter zentralwärts sind an manchen Stellen weit verbreitet noch eigentümliche, sehr grosse, ovale, keine scharfen Umrisse zeigende, sich ganz homogen färbende Zellen, welche einen kleinen exzentrischen Kern besitzen. Diese Zellen sind als vergrösserte, hypertrophische Gliazellen und nicht als Nervenzellen anzusehen, da sie nur in der weissen Substanz zu finden sind. Zugleich kommen auch Rundzellen in immer grösserer Zahl vor. Die Nervenelemente sind in diesen, so wie in den benachbarten, mehr sklerotisierten Zonen gänzlich verschwunden, an ihrer Stelle ist nur Bindegewebe, hypertrophisches Gliagewebe und eine diffuse Infiltration zu finden. Diese Partien umgeben gürtelmässig das innere erweichte Gewebe, woraus folgt, dass sie als eine reaktive Entzündungszone der Erweichung aufzufassen sind. Die Verteilung der Rundzellen ist auch weiter gegen die Mitte der Erweichung nicht gleichmässig; sie finden sich bald dichter, bald schütterer vor, bald umschliessen sie einige Gefässe ganz dicht, fast mantelförmig.

In der Mitte der Erweichung sind nicht nur die Nervenelemente, sondern anch das Gliagewebe verschwunden. Es ist nur ein Bindegewebsnetz zurückgeblieben', in dessen Maschen hie und da noch Rundzellen liegen. Körnchenzellen von ausgeprägtem Charakter finden sich nicht viele und nur an manchen änsserst seltenen Stellen erscheinen einige in deren Umgebung noch scholliges, grünlichschwarzes Pigment enthaltende Zellen liegen. Die Funktion der Körnchenzellen scheint also wenigstens zum grössten Teile aufgehört zu haben. Das zurückgebliebene Netz ist dicht, nur an kleineren Flecken wird die Substanz ganz locker, wo sich in der Mitte der Erweichung umschriebene, kleine Höhlen finden, deren Wände durch neugebildetes Bindegewebe gebildet werden.

Auch in diesem Falle finden sich unmittelbar unter der Pia oder dem Ependyma keine Erweichungsherde.

Der ganze mikroskopische Befund deutet also auf einen Erweichungsprozess hin, der schon abgelaufen ist und dessen Fortschreiten in der letzten Zeit nur ein äusserst langsames war.

Die vorhandenen primären entzündlichen Veränderungen betreffen hauptsächlich die weichen Meningen, doch dehnen sich dieselben auch anf die Gehirnrinde ans. 
Die weichen Hirnhäute sind fast überall infiltriert und verdickt. Am wenigsten ist die Pia am Gipfel der Gyri infiltriert, am meisten die in die Gehirnsubstanz eindringenden Septen, wo, besonders um die Gefässe herum, eine grosse Anhäufung von Zellen gefunden wurde. Am intensivsten ist die Entzündung der Pia entlang der rechten Art. fossae Sylvii. Hier ist die Pia mehrfach verdickt, zellenreich und diffuse oder in Haufen stark infiltriert. Die Entzündúng der Adventitia scheint ganz unmittelbar mit der der Pia zusammenzuhängen. Die Infiltration dringt auch in die Gehirnrinde ein, die in einem solchen Grade sich verändert hat, dass ihre Struktur nicht mehr erkennbar ist. Die Grenze zwischen der Pia und der Gehirnrinde ist nicht zu unterscheiden. Die Gehirnsubstanz ist hydropisch aufgequollen, die Nervenelemente und zum grössten Teile auch die Gliazellen sind verschwunden. Ihr Raum wird durch zahlreiches, stark infiltriertes, entzündliches junges Gewebe eingenommen, das auch neugebildete kleine Gefässe besitzt.

\section{III.}

Anamnese: E. F. 21jährige Dienstmagd aufgenommen in die Klinik für Nerven- und Geisteskranke am 24. Juli 1903.

Hereditäre Belastung ist nicht nachweisbar. Patientin war angeblich nie schwer krank. Seit einem Jahre kann sie den Urin nicht halten. Sie wurde aus dem städtischen Gefängnisse durch die Polizei auf die Klinik gebracht. Da sie verwirrt ist, kann sie keine verständliche Auskunft über ihre Krankheit geben.

Status praesens: Die Kranke ist stark abgemagert, minder kräftig gebaut. Die Konjunktiva erscheint bläulich, beide Augen sind injiziert. Die Pupillen sind mittelweit, reagieren äusserst träge. Das rechte Augenlid kann die Kranke nur halb schliessen. Der rechte Mundwinkel steht tiefer. als der linke. Die Bewegung der Gaumenbögen ist träge, paretisch. Die Funktion der Sinnesorgane war wegen der bestehenden Verwirrtheit nicht zu untersuchen. Die Bewegung der rechten Körperhälfte ist etwas paretisch. Der Gang ist unsicher, die Kranke schleppt den rechten Fuss. Der Patellarreflex ist am rechten Fusse gesteigert, an dem linken schwer auszulösen. Das Verhalten ist ruhig, das Bewusstsein trübe.

Die Kranke leidet an Pityriasis rosea Gibber. Die linken Submaxillardrüsen sind bis zur Grösse eines Hühnereies geschwollen. An der äusseren Seite beider Unterschenkel finden sich mehrere starke pigmentierte Narben. Aus der Urethra träufelt trübes, eitriges Serum, welches unter dem Mikroskope viele Eiterzellen und Gonokokken aufweist.

Die Sinneswahrnehmung ist äusserst mangelhaft, das Allgemeingefühl abgestumpft, die Stimmung gleichgültig. Die Orientierung scheint gänzlich aufgehoben zu sein. Die Erinnerung und Urteilsfähigkeit ist, soweit man es beurteilen kann, äusserst mangelhaft.

Verlauf. In den ersten zwei Tagen gab sie noch auf Fragen eine ziemlich verständliche Antwort. Am 27. Juli in der Frühe bemerkten wir, dass die rechte Gesichtshälfte unbeweglich wurde, an der linken dagegen zeigte sich ein übertriebenes mimisches Spiel. Die Speisen, sowie 
der Speichel rannen rechts aus dem Munde. Das rechte Auge kann sie nicht mehr schliessen. Das altive Bewegen der rechten Extremitäten gelingt kaum. $\mathrm{Za}$ gehen ist sie ebenfalls kaum imstande.

Der Zustand verschlimmert sich von Tag zu Tag. Am 29. hängt der Kopf fortwährend nach der linken Seite. Gehen und sitzen kann sie nicht mehr. Vom 1. August an treten in der Rumpfmuskalatur bald rechts, bald links Erregungszustände auf. Die Extremitäten (auch die linken) werden zeitweise ganz steif. Die Kaumuskeln sind beständig in tetanischer Kontraktur. Manchmal dehnen sich diese Krämpfe auch auf die Kehlkopfmuskeln aus, alsdann atmet die Kranke stenotisch. Sie ist bewusstlos, lässt den Urin und den Stuhl unter sich. Nahrung nimmt die Kranke nicht mehr zu sich, sie wurde daher mittels der Sonde künstlich genährt. Der Kopf fällt nach links, die Augen blicken nach rechts. Der Kornealreflex fehlt. Die rechte Facialislähmung ist eine totale geworden. Die Körpertemperatur ist beständig hoch: zwischen $39^{\circ}$ und $40^{\circ}$.

Thr Zustand verschlimmert sich weiter, bis die Kranke am 4. August, abends 11 Uhr starb.

Sektions-Befund. Die Hautfarbe der abgemagerten weiblichen Leiche ist blass. An der Sakralgegend sind viele teils kleinere, teils grössere von der Oberhaut entblösste Stellen. Auf der äusseren Seite des linken Unterschenkels sind mehrere, verschieden grosse and verschieden gestaltete, bräunlich pigmentierte, sich strahlenförmig nach der Mitte einziehende Narben.

Der Schädel ist symmetrisch, und von mittlerer Dicke. Beide Parietalknochen sind neben der Sutura sagittalis beiläufig in der Grösse eines Hühnereies verdickt. Die Verdickung besteht aus spongiösem Gewebe mit feinen kleinen Knochenlamellen und ist auffallend blutreich. Die harte Hirnhaut lässt sich stellenweise schwer abziehen, da sie mit den weichen Hirnhäuten verwachsen ist. Die Innenseite ist von einer feinen blutigen Membran überzogen.

An der Gehirnbasis ist die linke Art. Fossae Sylvii am Anfange verdickt, derb und undurchgängig. Beim Betasten ist auch in der vorderen linken Hälfte des Circulus arteriosus Willisii eine Verdickung zu fühlen. Am Durchschnitt dieser soliden Stelle bemerkt man eine ziemlich symmetrische Verdickung der Gefässwand, während das Lumen durch einen in Organisation begriffenen, rötlichgrauen, festen Thrombus ausgefüllt wird. Die rechte Art. Fossae Sylvii ist ebenfalls derb, strangartig, am Durchschnitt assymmetrisch verdickt und durch einen roten Thrombus vollständig verschlossen. Die Thrombose betrifft beide Gefässe in der Länge von etwa $1 / 2-3 / 4 \mathrm{~cm}$. Übrigens sind die Basalarterien genügend gut erhalten; von einer Endarteriitis ist keine Spur vorhanden.

Die Seitenventrikel enthalten in normaler Menge reines Serum. Der vordere Teil beider Corpora striata ist weicher, hauptsächlich der der linken Seite, beide sind auch bedeutend blutreicher als die sie umgebende Gehirnsubstanz. Beim Einschneiden erscheinen die Konturen des linken Linsenkernes verschwommen, die des rechten sind dagegen scharf gezeichnet. Auch erstreckt sich die linke Erweichung viel tiefer in das Innere des Gehirnes; das linke Centrum semiovale ist ebenfalls weicher und blutreicher. 
Beide Tonsillen sind vergrössert. Beim. Einschneiden entleert sich Eiter. Die Schleimhaut ist im Bereiche des Kehllkopfeinganges eitrigfibrinös belegt. In der Pharynxwand ist ein kleiner Abszess.

Die Lungen sind aufgebläht, an ibrer hinteren Oberfläche sind mehrere dunkelblaue, eingefallene Stellen. Das Lungengewebe ist diesen entsprechend kollabiert and luftleer. In den Bronchien findet sich aspirierte Flüssigkeit.

Die Milz ist etwas grösser. Thre Hülle ist fleckenweise verdiclit und gräulich-weiss gefärbt.

Die Nieren sind normal gross. Die Nierenkapsel lässt sich etwas schwer abziehen. Die Oberfläche ist uneben, hauptsächlich sind auf der linken Niere viele linsen- bis erbsengrosse, sternförmig eingezogene, narbige Stellen.

An der vorderen Seite des rechten Leberlappens ist in der Mitte eine linsengrosse, dunkelblaue, narbige, eingezogene Stelle, welche in die Substanz der Leber bis $4 \mathrm{~mm}$ eindringt.

Die Schleimbaut der Vagina ist dunkelblau. Der Uteruskörper enthält dicken, zähen, grünlichen Eiter. Die Ovarien sind mit den Tuben und der Umgebung verwachsen.

Die übrigen Organe zeigen keine bemerkenswerten Veränderungen.

Diagnose. Endarteriitis syphilitica ei thrombosis arteriae fossae Sylvii utriusque. Encephalomalacia rubra corporis striati atriusque et centri semiovalis sinistri. Hyperostosis syphilitica calvariae. Atelectasia partialis pulmonum. Perisplenitis chronica fibrosa. Cicatrices verosimiliter syphiliticae renum et hepatis. Cicatrices syphiliticae cruris. Pyometra. Perioophoritis et perimetritis adhaesiva chronica. Haemorrhagiae subcutis ex contusione.

Mikroskopischer Befund. 1. Arterien. Auffallend in diesem Falle ist die tiefgehende Erkrankung der kleineren Arterien im Gegensatze zu den grösseren und den mittelgrossen Gefässen, deren Erkrankung bedeutend weniger fortgeschritten erscheint. Ja, es scheint, als ob ein grosser Teil der endarteriitischen Veränderungen der rechten Arteriae fossae Sylvii ein Folgezustand der Erkrankung der kleineren Arterien sei.

Die Intima ist zum grössten Teile exzentrisch proliferiert. Thre Struktur zeigt nirgends ausgeprägte Schichten. In der linken Art. fossae Sylvii besteht die Intima fast überall aus länglichen, fortsatzreichen Bindegewebszellen, welche zerstreut in der homogenen Grundsubstanz liegen (Fig. Sd). Auch die Infiltration ist eine geringe. Nur an einer Stelle, in einer Ausbuchtung der Membrana elastica interna, wo eine kleinere Arterie heraustritt, ist die Struktur der Intima einem Granulationsgewebe gleich, indem wir hier ein äusseres zellenreiches, aus jungen Bindegewebszellen bestehendes, stark infiltriertes Gewebe treffen, in welchem auch zahlreiche neugebildete Blutgefässe sich finden (Fig. 6 e). Dieses Granulationsgewebe scheint nicht im Zusammenhange mit dem ähnlichen Gewebe der benachbarten Adventitia zu stehen. Es hat vielmehr den Anschein, als ob die Proliferation der Intima aus einem heraustretenden kleineren 
Zweige der Art. fossae Sylvii in diese eingedrungen wäre. Neben der histologischen Struktur sprechen für diese Annahme auch die Konsequenzen - die Thrombose.

Die Intima ist nur in den kleineren Arterien so stark proliferiert, dass manchmal kaum ein kleines, ovales, exzentrisches Lumen zurückgeblieben ist (Fig. 6 g). Die proliferierte Intima hat überall den Charakter eines frischen Granulationsgewebes. In einer kleineren Arterie ist sogar das ganze Lumen durch Granulationsgewebe ausgefüllt und nar die noch fast unversehrt zurückgebliebene Elastica deutet darauf, dass hier das Arterienlumen gewesen ist (Fig. $6 \mathrm{~g}$ ). Elastische Fasern oder Degenerationserscheinungen fanden sich in der neugebildeten Intima nirgends vor.

In den äusseren Schichten der Intima der linken Art. fossae Sylvii ist die Struktur stellenweise grobgekörnt, stellenweise lassen sich Konturen roter Blutkörperchen gut nnterscheiden. Es ist daher wahrscheinlich, dass es sich um einen roten Thrombus handelt, der sich organisiert hat. Nach innen übergeht die Intima ohne scharfe Grenzen in die Thromben, die nach aussen mit einer, aus fadenförmigen hyalinen oder grobscholligen Fibrinmasse, aus wenigen Überresten der roten Blutkörperchen und vielen weissen Blutzellen bestehender Zone umgeben und von frischen Bindegewebszellen stark durchsetzt sind. Innerhalb dieser Zone liegt ein roter Thrombus, welcher viel jünger als die ihn umgebende Zone ist, der sich aber, wie die hier und da zum Vorschein kommenden Bindegewebszapfen beweisen, anch schon auf dem Wege der Organisation befindet. Das übrig gebliebene exzentrische, ovale Lumen wird überall von konzentrischen länglichen Zellen (Endothel) umgeben (Fig. $6 \mathrm{f}$ ).

Die rechte Art. fossae Sylvii ist auch in ähnlicher sekundärer Weise verschlossen (Fig. 7). Endarteriitische Proliferation ist in ihr kaum zu sehen, das Lumen wird zum grössten Teile durch einen älteren, roten Thrombus eingenommen, so dass nur ein exzentrisch liegendes, kleines, ovales Lumen bestcht. Spuren der Organisation sind hauptsächlich nur an der Peripherie zu sehen. Die Oberfläche des Thrombus wird durch eine Zone von weissen Blutzellen gebildet. Auch das eingeengte Lumen ist zum grössten Teile durch rote, frische Thromben ausgefüllt.

Die Membrana elastica interna ist im allgemeinen in auffallender Weise unverändert, was besonders in den kleineren Arterien ins Auge fällt, wo alle anderen Gewebselemente durch Granulationsgewebe substituiert worden sind und die Elastica sich trotzdem fast unversehrt erhalten hat (Fig. 6). Bemerkenswert ist aber, dass sie an grösseren Strecken nicht den gewöhnlichen, schlängelnden Verlauf zeigt, sondern gerade verläuft (Fig. 7 a). Letzteres ist vielleicht die Konsequenz des gesteigerten inneren Druckes, da dieser Zustand immer nur an solchen Stellen zu finden ist, wo die stark angegriffene Media keinen Widerstand leisten konnte. Degenerationserscheinungen (fleckige Färbung, Teilung in mehrere Lamellen) kommen nur ausnahmsweise vor.

Auch die Media ist in den meisten Arterien relativ wenig verändert. Infiltration ist in ihr kaum $\mathrm{zu}$ finden. In der rechten Art. fossae Sylvii ist sie jedoch in einem beträchtlichem Bogensegment stark erkrankt (Fig. $7 \mathrm{f}$ ). An den Rändern der Erkrankung scheinen einige Rundzellen 
von der Seite der Adventitia einzudringen, doch bald wird die Infiltration immer dichter, die Muskelzellen degenerieren und verschwinden und es bleiben nur einzelne zerstreute Zellen übrig; schliesslich wird das spezifisch erkrankte Gewebe durch Rundzellen, auffallend vielen polynuclearen Leukocyten und neugebildeten Bindegewebszellen ausgefüllt. Neben dieser starken Erkrankung der Media besteht in der Intima überall nur die schon beschriebene Thrombose. Die Media der kleineren Arterien ist trotz der starken Veränderungen der Intima und Adventitia auffallend unversehrt.

Die Adventitia ist überall in einem stark entzündetem Zusiande. Sie ist fast überall durch zablreiche nengebildete Bindegewebszellen und einer dichten Infiltration verdickt. An den beiden Art. fossae Sylvii ist sie im Gegensatze zu der Intima am stärksten angegriffen (Fig. 6 a u. 7). Die Infiltration ist in den äusseren Schichten dort am dichtesten, wo die Lymphzellen sich ganz dicht nebeneinander gedrängt haben. Die Adventitia enthält ausserdem an vielen Stellen noch neugebildete Gefässe, so dass sie in den kleinen Arterien ganz die Struktur eines stark infiltrierten Granulationsgewebes gewinnt (Fig. 6 a), die dem Gewebe der proliferierten Intima ganz ähnlich ist. Trotzdem konnte ein Zusammenhang zwischen den beiden Geweben nicht nachgewiesen werden.

Spezifische Entzündungsprodukte, wie Riesenzellen oder miliare Gummata waren nicht zu finden. Die Infiltration ist um die beiden Art. fossae Sylvii zwar sehr dicht und erfolgte hanfenweise, doch war nirgends käsige Nekrose nachzuweisen.

2. Gehirnsubstanz. Die mikroskopischen Präparate weisen, entsprechend dem Sektionsbefunde, an der linken Seite auf einen unfangreicheren und älteren, auf der rechten auf einen geringeren und jüngeren Erweichungsprozess hin.

Die Erweichung fängt auch hier mit Auflockerung des Gliagewebes an. Die ganze Gehirnsubstanz scheint mit Serum durchtränkt zu sein. Die Nervenzellen werden träb, verfallen bald und verschwinden gänzlich, so dass nur ein loses, spongiöses Glianetz übrigbleibt. Nur das um die Gefässe liegende Bindegewebe bleibt scheinbar unversehrt, was mit dem allgemeinen Zerfalle im lebhaften Gegensatze steht. Diese Zone übergeht bei der Erweichung der linken Seite bald in eine äusserst zellenreiche Zone, in deren Bereiche die Grundsubstanz kaum mehr zu ersehen ist. Die rundlich ovalen, fortsatzlosen, in ihrem gekörnten Plasma mit einem exzentrischen Kern versehenen Zellen, welche diese Zone bilden, scheinen aus der Metamorphose der Gliazellen zu stammen. In den äusseren Schichten finden sich viele Übergangsformen zwischen den eigentlichen Gliazellen und diesen Körnchenzellen, welche nur in der Mitte der Erweichung typischen Charakter erhalten.

In diesen Übergangszonen der Erweichung sind an manchen Stellen äusserst zahlreiche, kleinere grössere Gefässe zu sehen, die prall mit Blut gefüllt sind, und in deren Nachbarschaft auch die grösste Zellenanhäufung stattgefunden hat.

Die Mitte der Erweichungsherde besteht fast ausschliesslich aus aneinander gedrängten Körnchenzellen, zwischen denen zahlreiche, vielleicht auch neugebildete, kleinere-grössere, aber immer blutreiche Blutgefässe und 
ein äusserst loses Bindegewebsnetz liegen. Auch finden sich an manchen Stellen kleinere leere Spalten. Grössere leere Räume haben sich jedoch nicht gebildet.

Bemerkenswert ist in diesem Falle auch, dass das Ependym und die unmittelbar unter demselben gelegene, einige Mikromillimeter dünne Schicht vollkommen gesund erscheint.

Ausser diesen Erweichungserscheinungen im engeren Sinne ist noch hauptsächlich an der Grenze der Erweichungsherde eine rundzellige Infiltration zu konstatieren. Dieselbe nimmt gewöhnlich um ein grösseres Gefäss Platz, kann aber auch um kleinere Gefässe, oder auch unabhängig von solchen, stattfinden.

Zwischen dem Bilde der Erweichung der beiden Seiten besteht ein beträchtlicher Unterschied. Die Zerfallszone ist an der rechten Seite nämlich viel umfangreicher als an der linken. An letzterer finden wir aber die Körnchenzellen äusserst massenhaft, während sie an der ersteren eben nur im Auftreten begriffen zu sein scheinen, so dass wir, auch die klinischen Erscheinungen ins Auge fassend, die Erweichung des rechten Corpus striatum für einen ganz frischen Prozess halten müssen, in welchem die Körnchenzellen noch keine Zeit zur Entwickelung hatten.

\section{Epikrise.}

Im Rahmen dieser Abhandlung scheint es kaum möglich zu sein, sich mit der Literatur der Frage eingehend zu beschäftigen. Bei den zu erwähnenden Autoren finden wir ansführliche Literaturangaben.

Der erste der sich mit der luetischen Erkrankung der Gehirnarterien ausführlicher beschäftigte war $\mathrm{Heubner.}{ }^{1}$ ) Er versetzt den Sitz der Erkrankung in die Intima, in die Schicht zwischen dem Endothel und der Elastica. Die Zellen dieser sogenannten Längsfaserschicht der Intima beginnen durch Kernmitose sich massenhaft zu vermehren und das Endothel von der Fenestrata abzuheben, während jede angrenzende Schicht unverändert bleibt. Die Neubildung erfolgt in der Regel streifenweise, nur auf einer Seite der Arterien, später breitet sie sich ebenso in der Längs- wie auch in der Querrichtung aus. Die Zellen des neugebildeten Gewebes sind grösser. Später erhält die Neubildung dadurch, dass die Zellen sich voneinander entfernen, die Intercellularsubstanz sich vermehrt, eine ganz faserige Struktur. Bald nachher nimmt sie, indem aus der Adventitia auch Rundzellen einwandern, den Charakter eines Granulationsgewebes an. Heubner sah in der Neubildung auch Riesenzellen. Die Membrana elastica interna bleibt auch noch in den späteren Metamorphosen unverändert. Auch neue Blutgefässe entwickeln sich in diesem Zeitpunkte. Verfettung ist nirgends zu finden. Wenn die Neubildung in einem früheren Stadium zum Stillstand kommt, so bildet das Endothel, nach

1) Heubner, Die luetische Erkrankung der Hirnarterien. Leipzig 1874. 
Heubners Auffassung, seiner physiologischen Tätigkeit gemäss, eine neue Membrana fenestrata, so dass wir in solchen Fällen zweien, einer alten und einer neuen Elastica begegnen. In der weiteren Entwickelung ordnen sich die neugebildeten Zellen in Schichten: zu einer inneren und zu einer äusseren. Die letztere besteht aus sternförmigen Zellen. Bald verschwinden auch die Rundzellen. Das letzte Stadium ist am häufigsten die Vernarbung.

Von der Atheromatose unterscheidet sich dieser Prozess dadurch, dass die von der Syphilis verursachte Neubildung viel zellenreicher ist, nicht verfettet und sich viel schneller entwickelt. Die Neubildung kann nach $\mathrm{Heubner}$ nicht als spezifisch angesehen werden, es soll nur eine Eigentümlichkeit der Syphilis sein, dass sie auf das Endothel proliferierend einwirkt. Der Sitz der Erkrankung befindet sich meistens in den mittelgrossen Hirnarterien.

Diesen Ansichten Heubners widersprachen mehrere Autoren.

Nach Köster ${ }^{1}$ ) ist das primäre immer die Proliferation der Vasa vasorum, wovon anch die Neubildung der Intima abhängt. Er bewies, dass die endarteriitischen Prozesse immer den in der Media liegenden, an der Stelle der Verzweigung der Vasa vasorum sich entwickelnden, kleinen Entzündungsherden entsprechen und dass ein ähnlicher Prozess nur an solchen Gefässen vorkommen kann, welche Vasa vasorum besitzen. Von diesen dehnt sich die Erkrankung dann, teils durch die Einwanderung, teils durch das Einwachsen, auf die Intima aus, welche sich passiv verhält, da ihre Zellen sich nur vergrössern, eine eigentliche Zellvermehrung jedoch nicht auftritt.

Auch Baumgarten ${ }^{2}$ ) hält den Prozess in der Intima für einen sekundären. Nach ihm beginnt der primäre Prozess in der Adventitia, oder zwischen ihr und der Media als eine Infiltration, oder es entwickelt sich ein, später verkäsende Herde bildendes, Granulationsgewebe. Als spezifische Produkte sind nur die letzteren anzusehen, da keine Endarteriitis als für Syphilis charakteristisch betrachtet werden kann. Die in den Gefässwänden liegenden Gummata sind grösser als miliare Tuberkeln. Baumgarten beschreibt also die syphilitische Gefässerkrankung als eine Periarterïtis gummosa.

Nach Rumpf ${ }^{3}$ ) gehen die Veränderungen aus der Media und zwar am häufigsten aus den an der Grenze der Media und Elastica

1) Köster, Sitzungsberichte der niederrh. Gesellschaft für Natur und Heilkunde. Bonn 1875.

2) Baumgarten, Virchows Archiv 76 und 86.

3) Rumpf, Die syphilitischen Exkrankungen des Nervensystems. Wiesbaden. 1887. 
interna sich verzweigenden, feinen Kapillaren aus. Am Anfange des Prozesses treten aus den Kapillaren Pundzellen aus, welche durch die Membrana fenestrata in die Intima eindringen. Letztere reagiert auf diese Finwanderung mit einer Fntzündung. Es entsteht ein Granulationsgewebe, dessen Kapillaren aus der Media stammen. Dieses Granulationsgewebe kann während seiner Entwickelung einzelne Lamellen der Elastica interna abheben und dadurch bewirken, dass an einer Arterie auch zwei Elasticae zu sehen sind. Die Auffaserung der Elastika geschieht häufig. Die Erkrankung schreitet meistens nach innen fort (endomuskulär). Aber auch die feinen Kapillaren zwischen der Media und der Elastica externa können zur Ausgangsstelle des Prozesses werden. In solchen Fällen dehnt sich die Erkrankung nach der Adventitia aus (perimuskulär), woraus eine Periarteriitis gummosa entsteht. Die Erkrankung aber ergreift manchmal die Media selbst, in welchem Falle Aneurysmen zustande kommen. Die regressive Metamorphose besteht in der Vernarbung. Die schlecht ernährten Zellen können auch der Verfettung und der Verkalkung verfallen.

Die Literatur, besonders die der letzteren Zeit, wurde eingehend von Ernst Mayer ${ }^{1}$ ) zusammengefasst, der einen kurzen und klaren Überblick von dem jetzigem Stande der Frage gibt. Auch Abramow ${ }^{2}$ ) bringt ausführliche literarische Beiträge.

In der ganzen diesbezüglichen Literatur finden wir, die A usgangs stelle der syphilitischen Gefässerkrankung betreffend, drei Ansichten.

Nach der ersten Ansicht(He ubn er und seine Nachfolger: Joffroy, Létienne, Möller, Ewald und andere) ist die Ausgangsstelle die Intima.

Die zweite (Köster und Rumpf) hält die Media für den Sitz des primären Vorganges.

Die dritte Ansicht (Baumgarten, Marchand, Lamy, Brasch, Sottas, Hoffmann und viele andere) betrachtet die Adventitia und den Lymphraum zwischen der Adventitia und Media als Ausgangsstelle. Nach dieser ist nur die Periarteriitis spezifisch. Die Veränderungen der Intima sind auch nach der zweiten Ansicht nur sekundär.

Zwischen diesen entgegengesetzten Ansichten nahm schon Oppen-

1) E. Mayer, Syphilis des Zentralnervensystems. 1898. Zentralbl. f. allg. Pathologie und path. Anatomie. 9. Bd.

2) Abramow, Über die Veränderungen der Blutgefässe bei der Syphilis. Beiträge zur path. Anatomie und allg. Pathologie. 1899. Bd. 26.

Deutsche Zeitschr. f. Nervenheilkunde. XXX. Bd. 
heim ${ }^{1}$ ) einen vermittelnden Standpunkt ein, indem er annahm, dass alle drei Gefässwandschichten selbständig erkranken können. Andere (Bristowo, Hudelo und Alelekoff) versuchen auch die entgegengesetzten Meinungen zu vereinigen und bekräftigen die Ansicht, dass die Intima ebenso wie die Adventitia der Sitz der primären Erkrankung sein kann. Abramow, der seine Untersuchungen zwar nicht an den Gehirnarterien ausführte, spricht sich auch dafür aus, dass jede der Gefässschichten selbständig erkranken kann.

Wie es aus dem oben mitgeteilten histologischen Befunde meiner drei Fälle hervorgeht, haben wir es mit drei, in der Art und Weise der Erkrankung äusserst differenten, in dem Endresultate hingegen gleichen syphilitischen Arterienerkrankungen zu tun, die gewiss auch gemeinsame Züge besitzen. Eben da ich bei der histologischen Untersuchung meiner drei Fälle dreierlei ganz divergierende Resultate finden konnte, nehme ich zur Frage einen vermittelnden Standpunkt ein. Die Ursache dessen, dass der eine Teil der Autoren die Erkrankung der Intima für primär hält, der andere Teil aber mit der gleichen Bestimmtheit behauptet, dass immer die Media oder die Adrentitia zuerst erkranke, ist gewiss, wie es auch aus meinen Fällen zu ersehen ist, in der Verschiedenheit der Fälle zu suchen. Baumgarten und seine Anhänger beobachteten solche Fälle, in denen die Adventitia mehr infiltriert war und spezifische Herde in ihr zu finden waren, während in den Fällen Heubners und seiner Genossen die Proliferation der Intima das auffallendste war. Es scheint mir höchstwahrscheinlich, dass das Virus der Syphilis gleichzeitig die Intima, die Adventitia, oder auch die Media voneinander unabhängig angreifen kann.

Ich glaube nicht zu irren, wenn ich die beschriebenen Fälle, besonders den ersten Fall, für geeignet halte, meine Ansicht zu bekräftigen. Es sind nämlich in diesen Fällen fast alle die Veränderungen vorhanden, welche man als syphilitisch betrachtet. Aus ihnen wird es klar, wie proteusartig die Syphilis in ihren Erscheinungen ist, dass sie auch an einem so kleinen Organ, wie an einer Arterie an den verschiedensten Stellen in den verschiedensten Formen auftreten kann.

Die Grösse der angegriffenen Arterien betreffend ist es bemerkenswert, dass die Erkrankung sich hanptsächlich auf die mittelgrossen Arterien der Gehirnbasis lokalisiert. Im zweiten Falle sind eher die grösseren (Art. basilaris, fossae Sylvii) erkrankt. Manchmal findet sich auch eine Veränderung der kleineren Zweige (3. Fall).

1) Oppenheim, Zur Kenntnis der syphilitischen Erkrankungen des zentralen Nervensystems. Berlin 1890. 
Zuweilen kommt auch eine Erkrankung der kleinsten Arterien vor, die jedoch nur in einer perivaskulären Infiltration besteht.

Was die Lokalisation der Erkrankung in der Gefässwand anbetrifft, halte ich aus dem mikroskopischen Befunde aller drei Fälle das folgende für wesentlich:

Schon bei der Beschreibung wurde hervorgehoben, dass die mittleren Schichten der Gefässwand: die Membrana fenestrata und die Media die geringsten Veränderungen zeigen. Am meisten resistent scheint die Membrana fenestrata zu sein, welche, abgesehen von der nur an wenigen Stellen beobachteten Aufquellung, Auffaserung oder den Rissen (hauptsächlich im 2. Falle) (Fig. 5 b) gar keine, oder nur eine sehr geringe Erkrankung zeigt. Auffallend ist die Resistenz der Elastika besonders an solchen Stellen, wo an ihren beiden Seiten schon altes, mit Blutgefässen versehenes, pigmentiertes Granulationsgewebe liegt; da erscheint sie trotz aller dieser Veränderungen unversehrt (1. und 3. Fall).

Die Media ist in den meisten Arterien nur in den vorgeschrittenen Phasen der Erkrankung verändert. Das normale Muskelgewebe wird zuletzt durch schnell vernarbendes Granulationsgewebe substituiert. Aber in der Mehrzahl der beobachteten Gefässe, wo wir schon einer starken Erkrankung der Intima und der Adrentitia gegenüberstehen, scheint sie kaum erkrankt und auch nicht infiltriert (1, 2. und 3. Fall) (Fig. 4 und 6). Fine Ausnahme bilden nur die rechte Art. fossae Sylvii des 3. Falles, wo eine starke aus der Adventitia stammende Infiltration die Media ergriffen hat (Fig. $7 f$ ) und diejenigen Fälle, wo eben nur die Media spezifisch erkrankt war (1. Fall) im Gegensatze zu der in diesen Präparaten auffallend wenig reränderten Intima und Adventitia (Fig. 1e).

Schon bei oberflächlicher Beobachtung scheint der unveränderte Zustand der mittleren Schichten jener Ansicht zu widersprechen, dass der Vorgang von aussen, aus der Adventitia sich auf die Intima ausdehne. Dieser Umstand scheint aber auch das Fortschreiten der Erkrankung in der entgegengesetzten Richtung - von innen nach aussen - zu verhindern. Es wird nur in den späteren Phasen möglich, dass in den inneren, der Intima am nächsten liegenden Schichten der Media sich auch Granulationsgewebe bildet, wo dann die mikroskopischen Bilder den Eindruck machen, als ob die Erkrankung von der Intima durch die löcherig gewordene Elastica interna auf die Media übergegangen sei (1. Fall).

Für die gegenseitige Unabhängigkeit der Vorgänge in der Intima und der Adventitia spricht, ausser dem Erwähnten, hauptsächlich der 
Umstand, dass sie selten einander entsprechen. Es geschieht zwar oft, dass an Stellen der Infiltration der Adventitia oder der miliaren Gummata auch die Intima am stärksten proliferiert ist, oder umgekehrt, dass entsprechend den am meisten proliferierten Stellen der Intima wir stärker infiltrierte Stellen der Adventitia begegnen, doch öfter noch finden wir eine stark proliferierte Intima dort, wo die Adventitia kaum infiltriert ist, oder umgekehrt, dort, wo die Adventitia schon stark angegriffen erscheint, ist kaum eine Spur der Endarteriitis zu finden. Dagegen, als wäre die Proliferation der: Intima nur eine entzündliche Reaktion wider die, von den Vasa vasorum eingetretene Rundzelleneinwanderung, spricht das Missverhältnis zwischen der Infiltration und der Proliferation, was sich in den jüngeren Vorgängen darin äussert, dass die letatere unverhältnismässig stärker ist. Manchmal sogar ist eine Infiltration dort, wo die Proliferation schon einen beträchtlichen Grad erreicht hat, kaum zu konstatieren (1. und 2. Fall).

Wenn es wirklich so wäre, dass die Erkrankung von der Adventitia oder Media auf die Intima sich verbreitete, so müsste die Intima gerade in den Fällen am stärksten angegriffen sein, wo auch die Media am stärksten erkrankt ist. Die mikroskopischen Präparate zeigen aber in manchen Fälllen gerade das Gegenteil, da eben bei der stärksten Infiltration der Media keine Endarteriitis vorhanden ist (Art. fossae Sylvii des 3. Falles) (Fig. 7).

Die Vorgänge in der Intima erscheinen fast überall (besonders im 1. und 2. Falle), wo sie überhaupt vorkommen, älter, mehr fortgeschritten, als die der umgebenden Schichten, so dass ich auf Grund aller dieser Befunde der Meinung beipflichten muss, dass das Virus der Syphilis unmittelbar auf die Intima wirkt und fähig ist, deren Proliferierung zustande zu bringen.

Was die histologische Struktur der neugebildeten Intima anbelangt, sind mehrere Typen zu unterscheiden:

1. In den Fällen, wo auch die klinjschen Erscheinungen auf einen mehr chronisch sich entwickelnden Prozess weisen, bedingt die histologische Struktur ebenfalls einen langsamen Vorgang. Das neugebildete Gewebe besteht in diesen Arterien nur aus zerstreut liegenden, manchmal in konzentrischen Reihen geordneten fortsatzreichen Zellen, die in eine gallertartige homogene Grundsubstanz eingebettet sind. (Besonders im 2. Falle.) Die Infiltration ist in solchem Gewebe äusserst spärlich (Fig. $4 \mathrm{~d}$ ).

2. Wo aber auch der klinische Verlauf auf einen akuten Vorgang weist, ist die Struktur der neugebildeten Intima diejenige eines gewöhnlichen Granulationsgewebes, sie besteht nämlich aus dicht neben- 
einander liegenden, grossen Bindegewebszellen, zwischen denen auch frische Kapillaren und eine starke Infiltration $\mathrm{zu}$ finden sind (1. Fall und kleine Arterien des 3. Falles) (Fig. $6 \mathrm{~g}$ ).

Es können aber auch mebrere Übergangsformen vorkommen, die sich schichtenweise aufeinander lagern: die äusseren Schichten sind gewöhnlich zellenärmer mit sternförmigen Zellen in der homogenen Grundsubstanz, die inneren sind dagegen immer zellenreicher mit länglichen konzentrisch geordneten Zellen, so dass in ihr manchmal ganz umschriebene Schichten zu unterscheiden sind.

Auch über das Verhalten der Membrana elastica interna und der elastischen Fasern in der neugebildeten Intima finden wir bei fast allen Autoren einige Angaben. Heubner konstatierte die Bildung neuer elastischer Membrane in der proliferierten Intima, über deren Bildung er der Meinung ist (wie es schon erwähnt wurde), dass die elastische Schicht das Produkt der physiologischen Aktivität des Endothels sei. Es bilde sich also immer eine neue Elastika dann, wenn die Zellen des Endothels wieder in ihren normalen Zustand gelangen, was auch dann der Fall st, wenn der Vorgang schon ein Ende gefunden.

Heubners Befunde wurden seitdem von mehreren Autoren anerkannt (Wendeler, Stanziale, Wickel und andere). Im Gegensatze aber beobachteten mehrere Autoren (besonders v. Rad und Pick, ausserdem Marchand, Alelek off und mehrere andere) die Auffaserung der alten Membrana fenestrata und fanden, dass zwischen den Lamellen der aufgefaserten Elastika neugebildetes Gewebe lag.

In den besprochenen drei Fällen ist das Verbalten der elastischen Fasern in der Intima sehr verschieden. Meistens finden sich in der verdickten Intima gar keine elastischen Fasern (1. und 3. Fall), in anderen Fällen ist im Gegenteil die Intima von elastischen Fasern ganz durchsetzt, welche entweder durch die Auffaserung der Membrana elastica interna zustande gekommen (einige Arterien des 1 . und viele des 2. Falles), oder ganz selbständig, offenbar unabhängig von der Membrana fenestrata gebildet worden sind (Arterien des 2. und eine des 1. Falles) (Fig. 5 d und e).

Die Neubildung elastischer Fasern ist wohl oft anzutreffen, aber nie bei frischen Prozessen, sondern nur in solchen Fällen, wo nicht nur der klinische Verlauf, sondern auch der mikroskopische Befund darauf hinweisen, dass der Erkrankungsprozess äusserst langsam fortgeschritten ist. Solche neugebildete elastische Lamellen schlängeln sich meistens unter dem Endothel unmittelbar um das zurückgebliebene Lumen. Manchmal aber bilden sich auch inmitten der proliferierten Intima ganz selbständige konzentrische Schlingen feiner elastischer 
Fasern (Fig. 5 d) (2. Fall). Letztere teilen dadurch das ganze intimale Gewebe in Etagen, welche auch histologisch voneinander different sind, so dass wir tatsächlich den Eindruck gewinnen, als ob die Intima sich schichtenweise aufgelagert habe und deren Bildung immer in grösseren oder kleineren Zeiträumen erfolgt sei. Unser histologischer Befund scheint also die Annahme Heubners zu bestätigen, indem es nahe liegt, diese neugebildeten, feinen, elastischen Fasern als solche zu betrachten, die während dem Stillstehen des Prozesses als physiologisches Produkt des Endothels zustande gekommen sind. Die Bildung solcher elastischer Lamellen kommt übrigens bei, durch die verschiedensten Ursachen verursachten, Endarteriitis vor, wenn deren Ablauf ein chronischer ist, so besonders bei der Arteriosklerose, wie es Thoma und neuerdings Jores') beobachteten. Man kann demnach dem Verhalten des elastischen Gewebes in der Histologie der syphilitischen Gefässerkrankung keine allzu grosse Bedeutung beimessen, weshalb wir auch der Meinung Wendelers und Schwarz' nicht beipflichten können, welche gerade die sich schichtenweise neubildende Elastika für die Syphilis charakteristisch halten.

Die spätere Entwickelung und die Metamorphosen der Endarteriitis weisen auch in meinen Präparaten auf solche Prozesse, die bereits ron vielen Autoren beschrieben wurden. So zum Beispiel dehnt sich die Proliferation zwar meistens auf den ganzen Querschuitt der Intima aus, aber in ungleichmässiger Weise, so dass das Lumen exzentrisch gelagert wird. Auch wächst die Proliferation den Arterien entlang und kann daher aus kleineren in grössere Arterien hinein (oder umgekehrt) wachsen, wie es am ausgeprägtesten die linke Art. fossae Sylvii des 3. Falles zeigt (Fig. 6e). Das spätere Fortschreiten der Proliferation geschieht noch weniger regelmässig. Marchand beobachtete in der Art. basilaris, Wickel in der Art. fossae Sylvii die Überbrückung des Lumens durch die neugebildete Intima, ja sogar die Bildung ganzer Septen. Weygandt beschrieb einen zapfenförmigen Fortsatz der Intima, welcher das Lumen in zwei Hälfte teilte. Ähnliche Veränderungen kommen auch in meinen Fällen vor. Die neugebildeten Bindegewebszellen bilden an vielen Stellen gut ausgeprägte, rundliche Knoten, welche sich meistens ganz scharf von dem sie umgebenden Intimagewebe abgrenzen. Die Knoten können sich anch in das Lumen vorheben, welches dadurch äusserst verengt wird. Ich beobachtete sogar einen Fall, in welchem zwei ähnliche einander gegenüber liegende Gebilde verwachsen waren, so dass sie das Lumen

1) Jores, Über die Neubildung elastischer Fasern in der Intima bei Endarteriitis. Beiträge z. path. Anatomie u, allg. Pathologie. 24. Bd. 1898. 
zerklüfteten (1. Fall). Die Bildung von Septen und damit die Abgrenzung mehrerer Lumina, von denen aber immer noch ein grösseres Hauptlumen zu unterscheiden ist, kommt in mehreren Arterien vor (2. Fall, Art. fossae Sylvii).

Bei der Endarteriitis proliferans kann die fortschreitende Proliferation zu Obliteration führen (Fig. 2). (Arterien im 1. Falle und kleinere Arterien des 3. Falles.) Das letzte Stadium der Obliteration scheint die Thrombose zu bilden. Dies scheint durch meine schon erwähnte Beobachtung bestärkt zu werden, dass nämlich in dem zirkulären Ringe der Bindegewebszellen eine homogen-körnige Masse liegt, welche wahrscheinlich das Produkt zerfallener roter Blutkörperchen und Fibrins ist (1. Fall). An manchen Stellen ist auch die Organisation des Thrombus zu beobachten. Die Thrombose wird bedeutend im 3. Falle, indem hier (beide Art. fossae Sylvii) kaum eine Spur von Endarteriitis vorhanden, doch fast das ganze Lumen durch einen Thrombus obliteriert ist (Fig. 6). Die Ursache ist wahrscheinlich in der Verkleinerung des Lumens oder auch gänzlicher Versperrung der abzweigenden kleineren Arterien zu suchen.

Wenn die Obliteration vollkommen ist, so verschwindet langsam der Unterschied zwischen den äusseren und inneren Schichten der Intima. Die Intercellularsubstanz vermehrt sich, Blutgefässe bilden sich in grösserer oder kleinerer Zahl. (Dies wurde schon von Heubner, Simerling, Brasch, Alelek off und anderen konstatiert.) Die Infiltration ist zwar auch noch vorhanden, aber unregelmässig. Das alte Lumen wird mit der Zeit vollkommen von der noch mehr oder weniger gesund erscheinenden Membrana fenestrata umringt und durch ein, einem älteren Granulationsgewebe ähnliches Gewebe ausgefüllt (1. Fall, Fig. 2). In den Arterien aber, wo der Prozess nur langsam fortschritt (2. Fall) und sich demgemäss nur ein zellenarmes, gallertartiges Gewebe entwickelt hat, tritt in der Struktur keine so auffallende Veränderung auf. Übrigens scheint es in solchen Gefässen nie zu einer vollständigen Obliteration zu kommen. Von den auf die Arteriosklerose charakteristischen regressiven Metamorphosen, also in erster Linie der hyalinen Degeneration und Nekrose, sowie der Verkalkung, ist hier keine Spur zu finden.

Wenn ich es für wahrscheinlich gehalten habe, dass die Erkrankung der Intima, wenigstens zum grössten Teile, unabhängig von der der anderen Schichten auftreten kann, um so mehr muss ich auf Grund der geschilderten Befunde betonen, dass die Erkrankung der Adventitia und Media eine primäre sei. Dies wird auch dadurch bewiesen, dass ich, streng genommen, spezilischen Veränderungen in der Intima nicht begegnete, solche aber in der Media und Adventitia sich vorfanden. 
Wie schon erwähnt, ist die Media unter den drei Schichten diejenige, welche in den meisten Fällen nur wenig angegriffen ist. Am Anfange des Prozesses scheint sie sogar verdickt zu sein, wahrscheinlich durch die Verminderung des Blutdruckes, die durch die Proliferation der Intima zustande gekommen ist. In zwei Fällen aber bildete sie die am meisten angegriffene Schicht. Bei einer Arterie (1. Fall) liegt in ihr ein umschriebener Infiltrationsherd, der wahrscheinlich ein gummöses Gebilde ist (Fig. 1 e). Die Beschreibung eines ähnlichen Produktes fand ich in der bisherigen Literatur nicht. In einer anderen Arterie (rechte Art. fossae Sylvii des 3. Falles) ist die Media neben der kaum erkrankten Intima und auch weniger angegriffener Adrentitia in ansgedehnter Weise durch mono- und polynukleare Leukocyten stark infiltriert, wobei nebst der Infiltration auch neugebildete, lappige Bindegewebszellen sich vorfinden (Fig. $7 \mathrm{f}$ ). Als spezifische Produkte sind noch diejenigen Riesenzellen anzusehen, welche in einer Krümmung der Membrana fenestrata, umgeben von Bindegewebszellen, aufgefunden wurden (Fig: $2 \mathrm{~h}$ ).

Mit dem Fortschreiten des Krankheitsprozesses leidet später auch die Media. Abgesehen von den atrophischen Erscheinungen, bei denen es nicht genau zu bestimmen ist, welchen Anteil daran die Inaktivität (infolge der Verdickung) der Intima hat, halte ich diejenigen mikroskopischen Befunde für bemerkenswert, in denen im Zusammenhange mit der Erkrankung der Intima, meistens in deren fortgeschrittenen Stadien, ein dem obliterierenden Intimagewebe ganz identisches Granulationsgewebe zwischen der Elastica interna und der Muskularis sich entwickelt hat. Dieses Gewebe scheint von der noch gesund aussehenden Elastika die schon etwas abgezehrte, aber relativ noch wenig erkrankte Muskularis abzuheben (1. Fall). Die obenerwähnten Riesenzellen lagen auch in diesem Granulationsgewebe (Fig. $2 \mathrm{f}$ ).

In der Adventitia treten ausser der diffusen Infiltration und Vermehrung der Zellen, die schon oben exwähnten spezifischen Entzündungsprodukte: miliare Gummata (1. Fall, Fig. 3d) und herdförmige mit Zellenneubildung verbundene, gummöse Infiltrationen auf (2. und 3. Fall) (Fig. 6 a).

Die Bindegewebsvermehrung wird mit dem Fortschreiten der Erkrankung immer beträchtlicher, so dass sich in den meisten Arterien auch in der Adventitia (besonders im 1. Falle) eine diffuse, ungleichmässige Infiltration, mit durch Blutgefässen und Pigment durchsetztem Granulationsgewebe entwickelt, wie an ähnlichen Stellen der Intima und Media.

In den späteren Phasen der Erkrankung verlieren alle drei Schichten ihre ursprüngliche Struktur gänzlich und verwandeln sich in ein gleichförmiges, dem Granulationsgewebe mehr oder minder ähn- 
liches Gewebe. Darauf, dass hier einst eine Arterie vorlag, deuten nur die noch immer jeder Einwirkung hartnäckig widerstehende, manchmal in ihrem ganzen Ablaufe verfolgbare, aber dislozierte Membrana elastica, oder wenigstens deren aufgefaserte, seltener rissige Überreste (1. Fall, kleine Arterien des 3. Falles).

Auf Grund der beschriebenen Fälle kommen wir zu den folgenden Schlüssen:

Die Syphilis kann alle drei Schichten der Arterienwand ergreifen, am meisten verschont sie die mittlere Schicht. Sie verursacht in der Intima hauptsächlich eine intensive Proliferation, die zur Obliteration führen kann; in der am wenigsten angegriffenen Media und in der Adventitia erzeugt sie aber diffuse Entzündungen und umschriebene miliare Herde, bei welchen Veränderungen auch Riesenzellen vorkommen, welche als spezifische Produkte der Syphilis anzusehen sind. Die Entzündung der verschiedenen Schichten ist voneinander mehr oder minder unabhängig, besonders die der Intima von der Adventitia und umgekehrt, während die der Media mit der Entzündung der Adventitia in Zusammenbange zu stehen scheint.

In den späteren Stadien des Prozesses wird das Gewebe aller drei Schichten durch Granulationsgewebe ersetzt, nur die Membrana fenestrata widersteht allen pathologischen Einwirkungen.

Dem Verhalten des elastischen Gewebes bei der syphilitischen Erkrankung ist keine grössere Bedeutung zuzuschreiben, da dieselben Veränderungen auch bei anderen Erkrankungen der Intima auftreten. Die Neubildung des elastischen Gewebes steht im Sinne der Heubnerschen Hypothese übrigens mit dem Stillstande des Prozesses im Zusammenhange.

An der Erkrankung nehmen Arterien aller Grössen, von den kleinsten bis zu den grössten, teil.

Da bei der Endarteriitis das Lumen immer verengt wird und daher weniger Blut durchströmen lässt, werden die durch die erkrankten Arterien versehenen Gewebspartien schlecht, im Falle der Obliteration da kollaterale Anastomosen im Bereiche der subkortikalen Gehirngefässe nicht vorhanden sind, gar nicht ernährt. Sie unterliegen daher der Erweichung.

In den beschriebenen Fällen war die Gefässerkrankung stark verbreitet, sie verursachte demgemüss auch umfangreiche Erweichungen. Kurz gefasst betraf die Erweichung im ersten Falle hauptsächlich den rechten Stirnlappen, den linken Gyrus centralis, den linken Schläfenlappen und beide Corpora striata. Im zweiten Falle den vorderen Pol des rechten Temporallappens und beide Corpora striata. Im dritten 
Falle sind auch beide Corpora striata und links der Linsenkern mit der ihn umgebenden Partie des Centrum semiovale ergriffen. Da überall auch die entsprechenden nutritiven Arterien, welche zu den Erweichungsherden führen, angegriffen, ja sogar oft ganz obliteriert sind, ist der kausale Zusammenhang bestätigt.

Mit Bezug auf die mikroskopische Gestaltung der Erweichungen, will ich nur auf diejenigen grossen Unterschiede hinweisen, welche in den beschriebenen drei Fällen trotz derselben Ursache bestehen.

Im ersten Falle sind an den Erweichungen drei Zonen gut zu unterscheiden: eine äussere mit der Degeneration der Nervenelemente und Wucherung der Glia, eine mittlere, gebildet durch aneinander gedrängte Körnchenzellen, und eine innere, wo nur Bindegewebe und Blutgefässe als ein gleichmässiges "état criblé" zurückgeblieben sind. Der Erweichungsprozess war also noch im Gange. Ausserdem sind noch hie und da im Zusammenhange mit kleineren Arterien miliare Gummata oder diffuse Infiltrationen und Riesenzellen zu finden.

Im zweiten Falle umgibt das innen liegende „état criblé eine aus hypertrophisiertem Gliagewebe und Bindegewebe bestehende, scheinbar sklerotisierte Zone, in deren Bereiche auch eine starke, reaktive, rundzellige Infiltration stattfindet. Körnchenzellen sind nur äusserst spärlich vorhanden. Die Erweichung scheint in diesem Falle also, im Gegensatze zu der vorigen, schon seit längerer Zeit kaum fortgeschritten zu sein, da sich die Ränder schon sklerotisiert haben. In diesem Falle schreitet eine diffuse syphilitische Entzündung in der Umgebung der rechten Art. fossae Sylvii auch auf die Gehirnsub$\operatorname{stanz}$ über.

Im dritten Falle ist eine äussere, umfangreiche Zone zu unterscheiden, deren Gewebselemente ausser dem Bindegewebe überall im Zerfalle begriffen sind. Die Mitte der Erweichung wird hier durch die Masse der Körnchenzellen gebildet. Das mikroskopische Bild weist also auf eine plötzlich aufgetretene, aknte Erweichung. Entzündliche Infiltration ist nur spärlich vorhanden.

Bemerkenswert ist es, dass Blutungen oder grössere Höhlen in den Erweichungsherden nirgends zu finden waren. Diese Umstände zeigen auch auf eine, die Ernährung des Gehirngewebes langsam vereitelnde Ursache hin.

Die Corpora striata waren in allen drei Fällen angegriffen, sie scheinen also eine Vorzugsstelle der Erweichung bei der syphilitischen Gefässerkrankung der Gehirnbasis zu sein. Die Erweichung liess aber die Ependyma und die unmittelbar unter ihr liegenden Schichten in allen drei Fällen unversehrt. Die Ursache davon liegt gewiss in den schon von Duret wahrgenommenen Anastomosen zwischen der Tela 
und der Ependyma, die die Ernährung der oberflächlichsten Schichten der Ventrikelwand ermöglicht.

Vergleichen wir also das mikroskopische Bild der Erweichungen mit dem der Gefässerkrankungen und betrachten wir die klinischen Symptome und die Krankheitsdekurse, so wird das auffallend Gleichartige aller drei Fälle offenbar. Die erwähnten Umstände weisen alle darauf hin, dass im ersten Falle ein schnell ablaufender, aber wie man aus den grossen Verwüstungen schliessen kann, etwas älterer Prozess stattgefunden hat. Im zweiten Falle haben wir es mit einem alten, fast vollendeten Prozess zu tun. Im dritten Falle war aber der Prozess plötzlich aufgetreten, akut.

Der mikroskopische Befund und das klinische Krankheitsbild decken sich in diesen Fällen so vollkommen, dass man, nach meiner Ansicht, in ähnlichen Fällen aus dem ersteren auf das letztere folgern dürfte.

\section{Erklärung zu Tafel II-IV.}

Figur 1. (1. Fall.) Miliare Gumma in der Media bei anfangender Endarteriitis:

a) proliferierende Intima, bj Membrana elastica interna, c) Media, d) Adventitia, e) Infiltrationsherd. Färbung: Hämatoxylin-Eosin.

Figur 2. (1. Fall.) Obliterierte Arterie mit Riesenzellen:

a) Intima, b) Membrana elastica interna, c) relatiy gesunde Media, d) Gefässlumina in der Intima, e) Infiltration in der Intima, f) Entzündliche Media, g) Pigment in der Lutima, h) Riesenzellen in der Media. Färbung: Hämatoxylin-Eosin.

Figur 3. (1. Fall.) Miliare Gumma in der Adventitia:

a) Membrana fenestrata, b) Media, c) gesunde Adventitia, d) miliare Gumma. Färbung: Hämatoxylin-Eosin.

Figur 4. (2. Fall.) Arteriitis mit starker Proliferation der Intima (Arteria vertebralis dextra):

a) Adventitia, b) Media, c) Membrana fenestrata, d) stark proliferierte Intima, e) neugebildete Gefässe. Färbung: Hämatoxylin-Eosin.

Figur 5. (2. Fall.) Auffaserung und Neubildung des elastischen Gewebes (rechte Art. fossae Sylvii):

a) stark infiltrierte Media, b) Membrana elastica interna mit Auffaserung, c) neugebildete Intima, d) 1, 2, neugebildete, elastische Fasern, e) feine elastische Fasern. Färbung: Resorcin-Fuchsin (starke Überfärbung).

Fig. 6. (3. Fall.) Entzündung mit starker Periarteriitis (linke Art. fossae silvii und deren kleinere $Z$ weige):

a) stark infiltrierte Adventitia mit neugebildeten Gefässen, b) Media, c) Membrana elastica interna, d) proliferierte Intima (gallertartiges Gewebe), 
e) Granulationsgewebe in der Intima (zurückgewachsen aus der kleinen Arterie), f) Thrombus, g) 1, 2 kleine Gefässe mit starker Endarteriitis. Färbung: Hämatoxylin-Eosin.

Figur 7. (3. Fall.) Entzündung der Media und Adventitia (rechte Art. fossae sylvii):

a) Membrana elastica interna, b) gesunde Media, c) Adventitia, d) Blut im zurückgebliebenen Lumen, e) älterer Thrombus, f) entzündete Media (Infiltration und Bindegewebsneubildung). Färbung: Hämatoxylin-Eosin.

Vergrösserung: Fig. 1, 2, 4, 5, 7 Okular 4, Objektiv 3 (Reichert).

" Fig. 3, Okular 4, Objektiv 5 (Reichert).

" Fig. 6, Okular 4, Objektiv 1 (Reichert). 